AAC Clinical Pathways for Neurodegenerative Disease

Chris Gibbons, Ph.D., CCC-SLP

Melanie Fried-Oken, Ph.D., CCC-Sp Oregon Health \& Science University Portland, Oregon

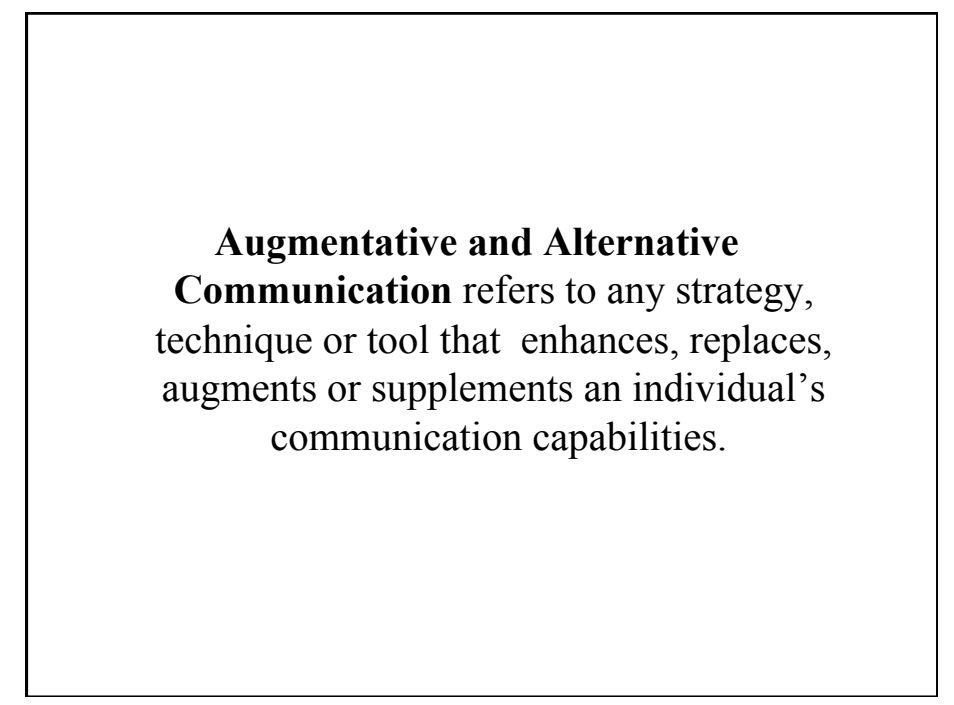

\section{Communication impairments} leading to AAC use

- Physical impairments

- ALS (Lou Gehrig's Disease)

- Cerebral Palsy

- Spinal Cord Injury

- Parkinson's Disease

- Multiple Sclerosis

- Cognitive impairments

- Traumatic brain injury

- Developmental Delay

- FTD, AD 


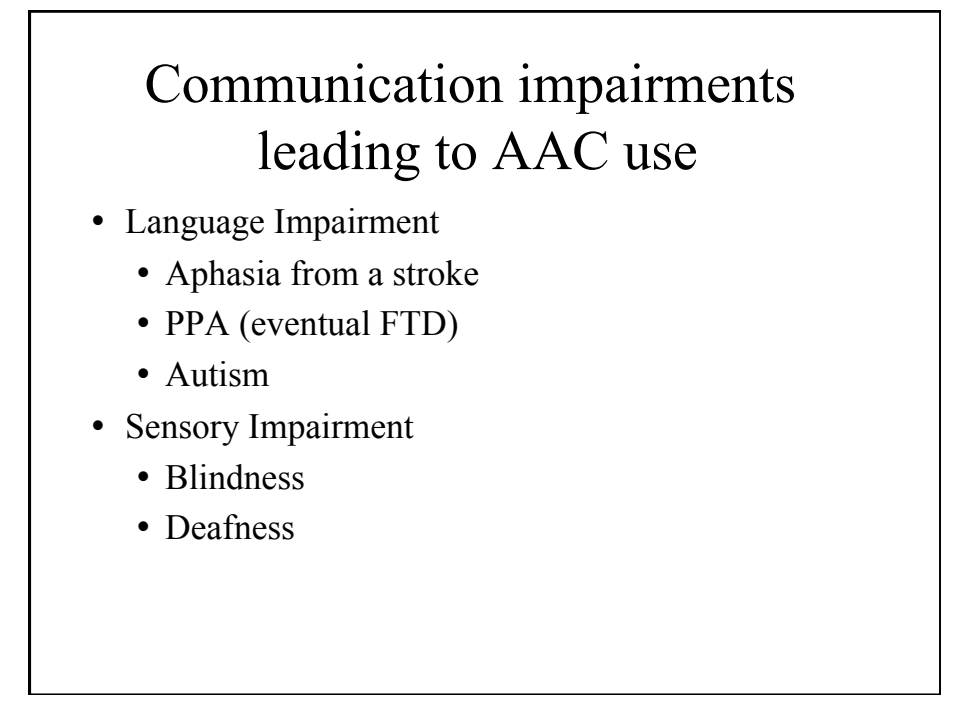

\section{AAC Across the Lifespan}

- Cause and Effect

- Concrete Referents

- Communication Context

- Dyadic Exchange

- Play

- Cognitive Development

- Language Development

\section{Augmentative Communication} Approaches

- Speech

- Vocalization

- Gestures

- Eye gaze

- Body language

- Sign language

- Paper and pencil

- Communication books

- Communication boards and cards

- Remnants

- For-purpose software

- Re-purposed software

- Voice output communication aids

\section{AAC Across the Lifespan}

- Peer interaction

- Academic Participation

- Broader Social Access

- Workplace Readiness/Participation

- Language Remediation

- Alternative Language Access

- Cognitive Cuing 


\section{AAC Across the Lifespan}

- Conversation Context Support

- Dyadic Support

- Symbolic Reference

- Visual/Physical Prompt

- Functional Memory Aid

- Direct Referent Cuing

- Basic Needs Choice Support

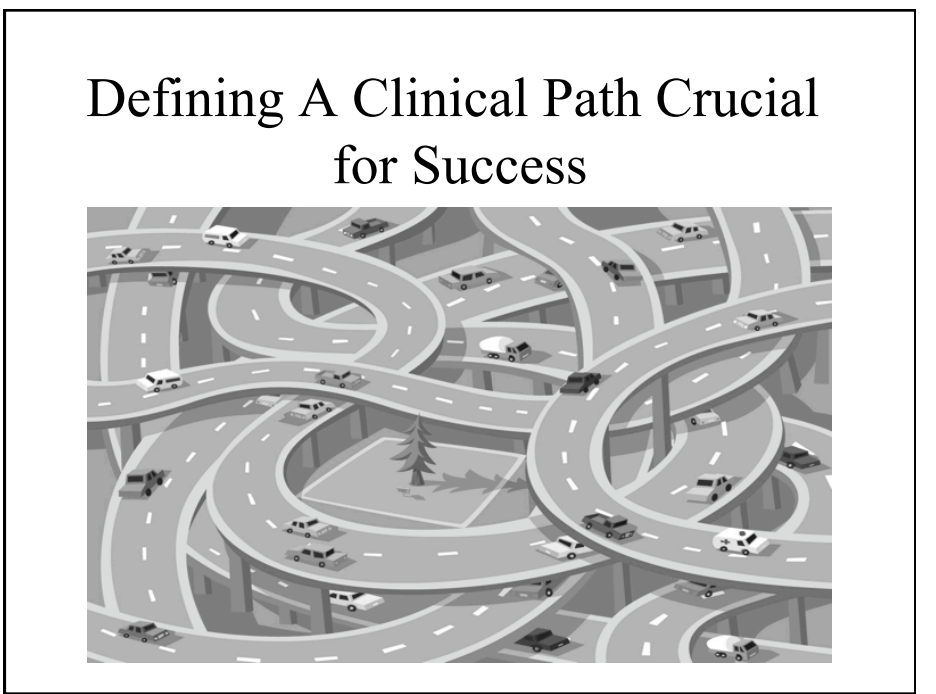

\section{AAC Clinical Path}

- Functional outcome drives goals and clinical path

- Function of AAC in various populations vastly different depending on

- Developmental trajectory

- Assumed course of condition/disease/disability/ remediation/cognitive stability

- Language knowledge/accessibility, etc.

\section{Defining the Path}

- We begin with a Participation Model of service delivery

- Participation, not Stimulation

- Participation model hinges on thinking differently about disability

- Focus on function, not disability per se 


\section{Defining the Path}

- Stress functional outcome

- Neurodegenerative diseases warrant wellconsidered clinical paths

- Will use 3 specific DX to guide discussion

- Look for where the lines intersect

- Use those points to inform specific functional approaches with neurodegenerative intervention

\section{Evaluation philosophy}

- For patients with neurodegenerative disease, the purpose of AAC is to provide tools and strategies so that an individual can continue to participate in daily life.

- AAC treatment is not necessarily based on assumptions to regain skills, improve skills, or even maintain skills.

\section{Amyotrophic Lateral Sclerosis}




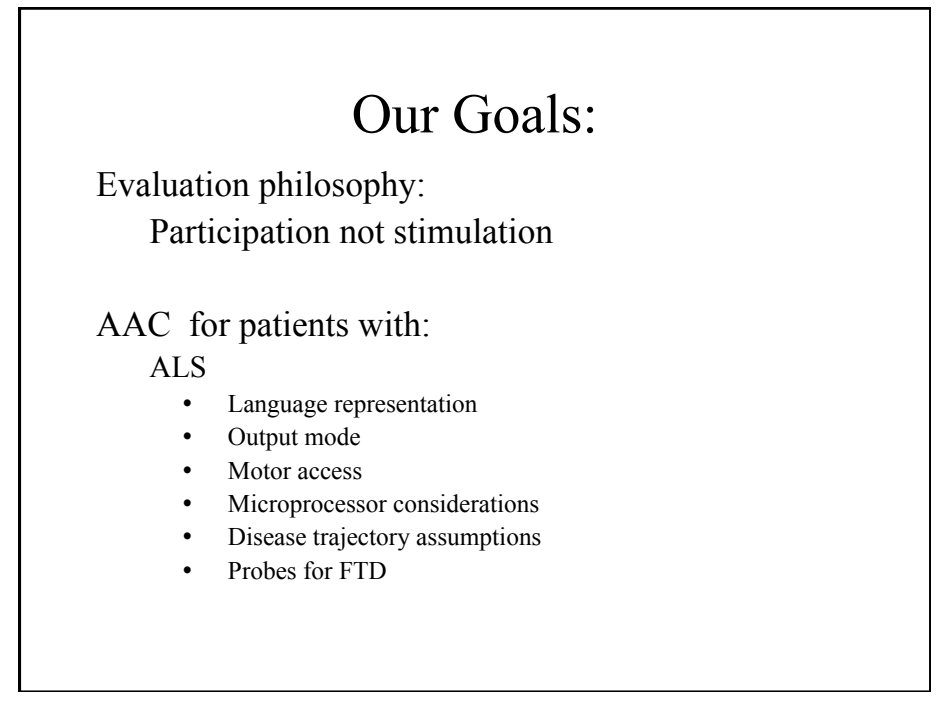

\section{Communication and ALS What Happens}

- Musculature enabling speech weakens. Most often the tongue first.

- Speech volume changes, softer, less able to modulate with emotion, prosody.

- Speech quality changes, rough, husky.

- Speech clarity changes, slurred sounding, hypernasal, reduced intelligibility, dysarthric.

\section{Do Not Communicate,} Where Am I?

- In the presence of ALS, the symphony of speech is problematic and vulnerable.

- $80 \%$ of pALS will lose their speech (Saunders, Walsh, \& Smith, 1981).

- "Loss of Speech" most frequently associated symptom with "worst aspect of disease" (Hecht et al., 2002).

- Devastating breakdown in social interaction, control, independence, identity.

\section{Communication and ALS What Happens}

- Limb onset $-75 \%$

- Bulbar onset - 25\%

- Concomitant FTD - 20\% but may be higher highly variable presentation

- Psuedobulbar effects highly variable

- About 10\% familial

- $90 \%$ sporadic (Guam, Italian soccer players, U.S. Military service most popularized risk groups) 


\section{Communication and ALS: Perspective Taking}

- Caregivers rate patients as having less energy and more suffering than patients rate themselves.

- Patients rate their caregivers as more burdened overall than caregivers rate themselves (Adelman et al. 2004).

- Even basic communication strategies can alleviate such misperception and help relieve emotional distress.

\section{How Should the Communication}

\section{Partner Look?}

- Ask questions appropriate to the communication system

- Respond

- Discuss the "rules" of communication openly and honestly

- Don't be afraid to request complicated information, but be prepared to wait

- Let the AAC users be who they are first, reinforce their identity and independence

\section{What Does the Communication} Partner Typically Look Like?

- Dominant socially/conversationally ("big people").

- Directive

- Unresponsive to AAC (avg. 7\% response).

- Anticipatory

- Question after question after question.

- Poor communication opportunity creators.

\section{Communication and ALS:}

- Given the appropriate systems, training and partner participation, pALS can continue to

- communicate with their spouse and children about "mundane" household decisions

- Manage their medical care

- Make important financial arrangements

- Be funny

- Impart comforting words to their caregivers and family

- Make new friends 


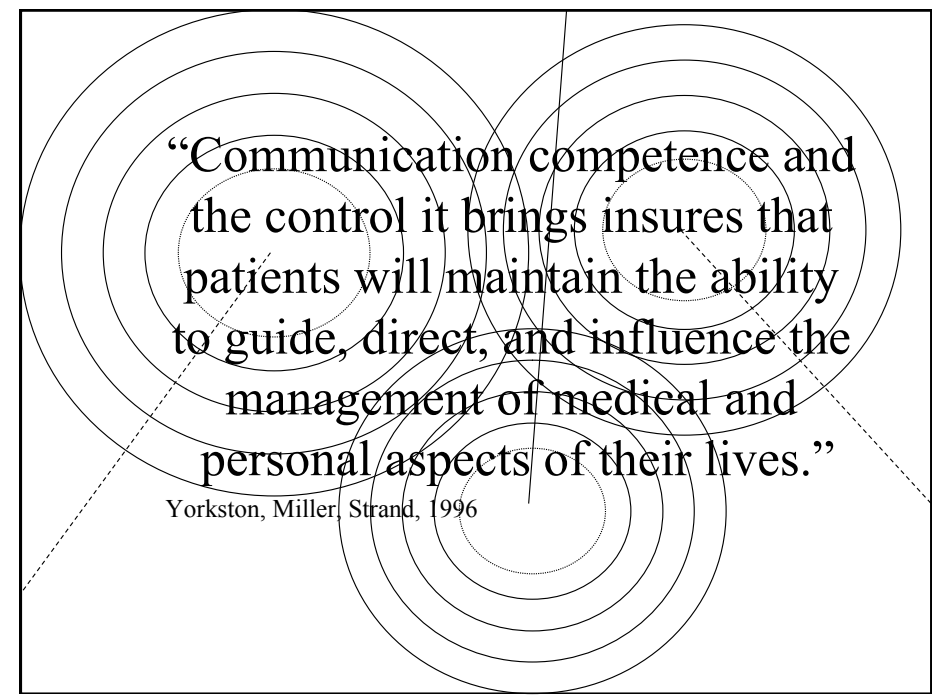

\section{Speech recognition}

- Dragon-Naturally Speaking

- Must have consistent speech production

- Mild-moderate dysarthria is adequate for _controlling computer with speech input.

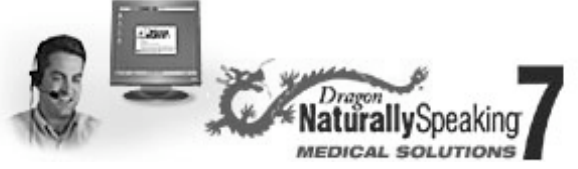

\section{What Does Communication for pALS Look Like?}

- It is comprehensive, not always complicated, and always changing.

- Verbal with amplification.

- Non-verbal (facial expression, eye blink Y/N, gesture, pencil/paper, communication board, E-Tran, etc.)

- Light Tech - multi-message speech playback.

- High Tech - computer-based software driven communication systems, voice output.

- It accommodates increasing physical disability.

- Alternative access (switch, head mouse, eye control, etc.)

\section{Voice Amplification Options}

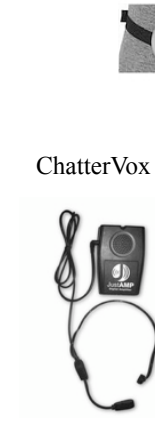

JustAMP or JusTalk JustMED, Inc. 503-524-4223

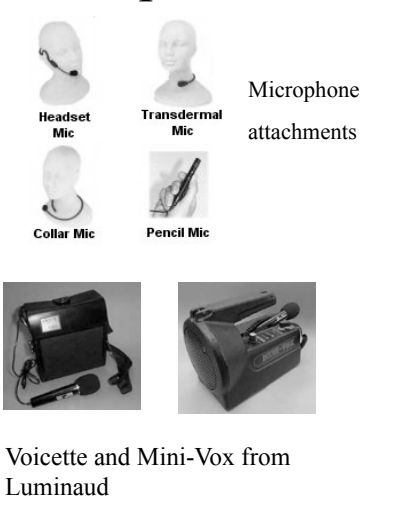



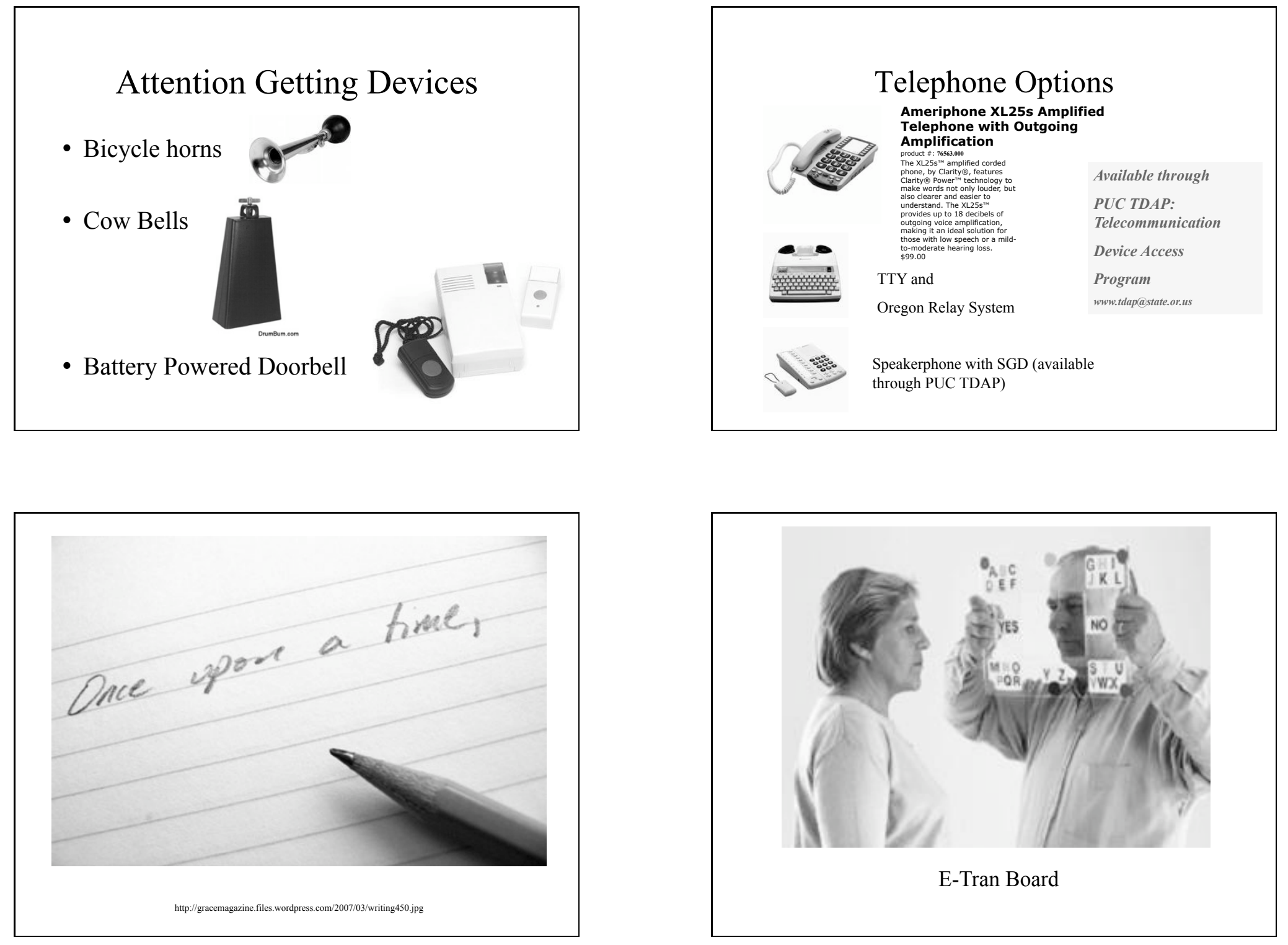

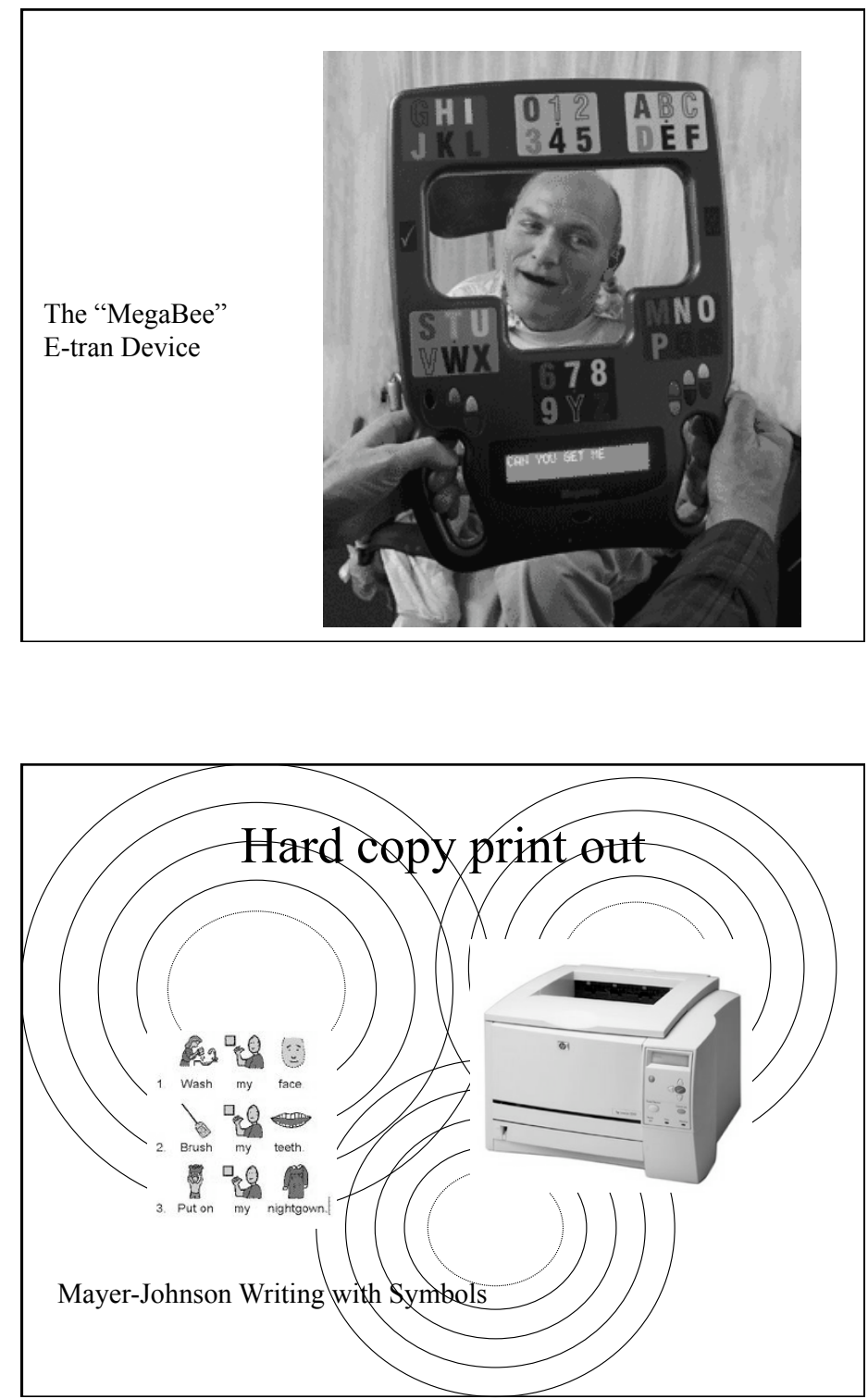
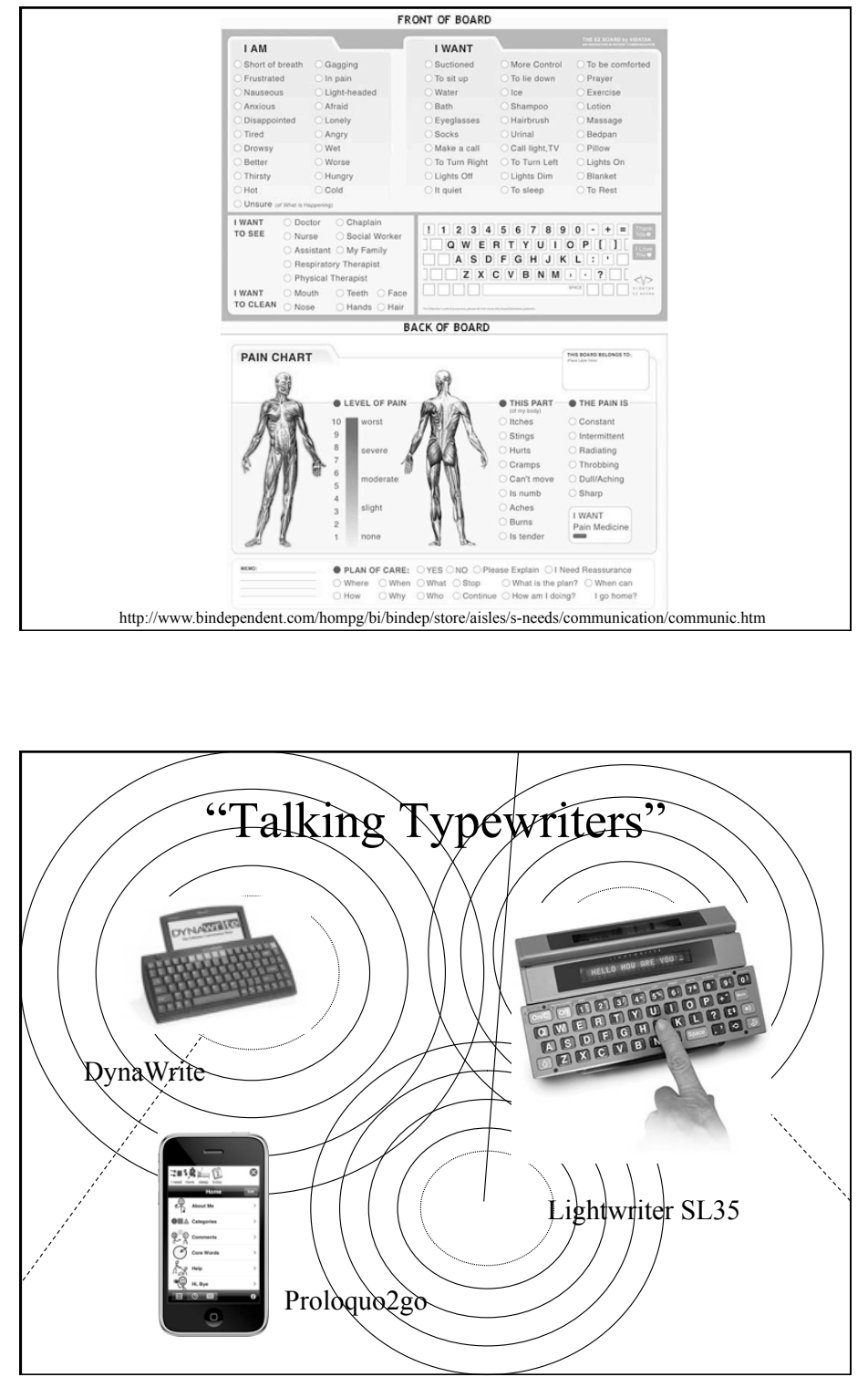

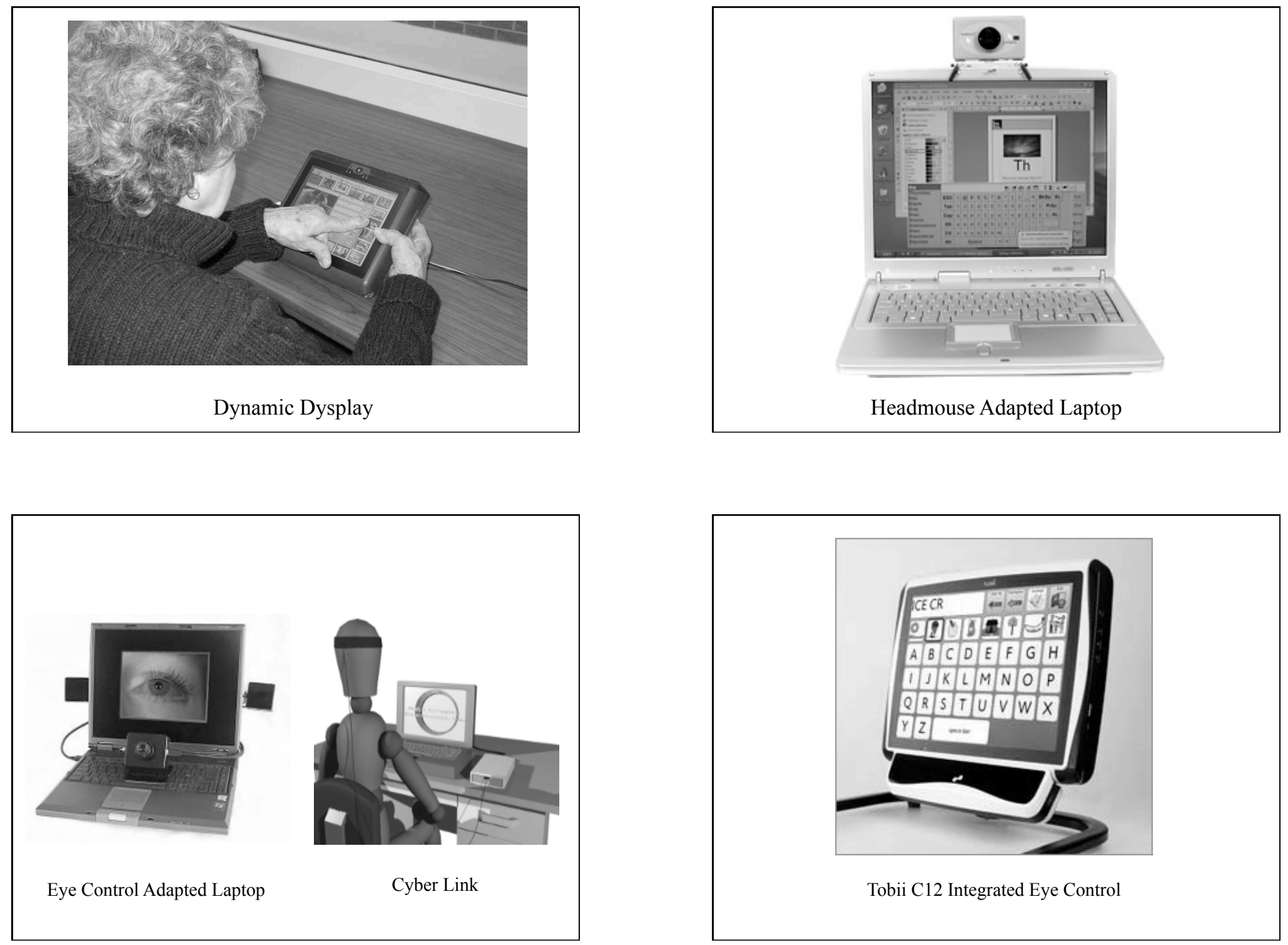

Tobii C12 Integrated Eye Control 


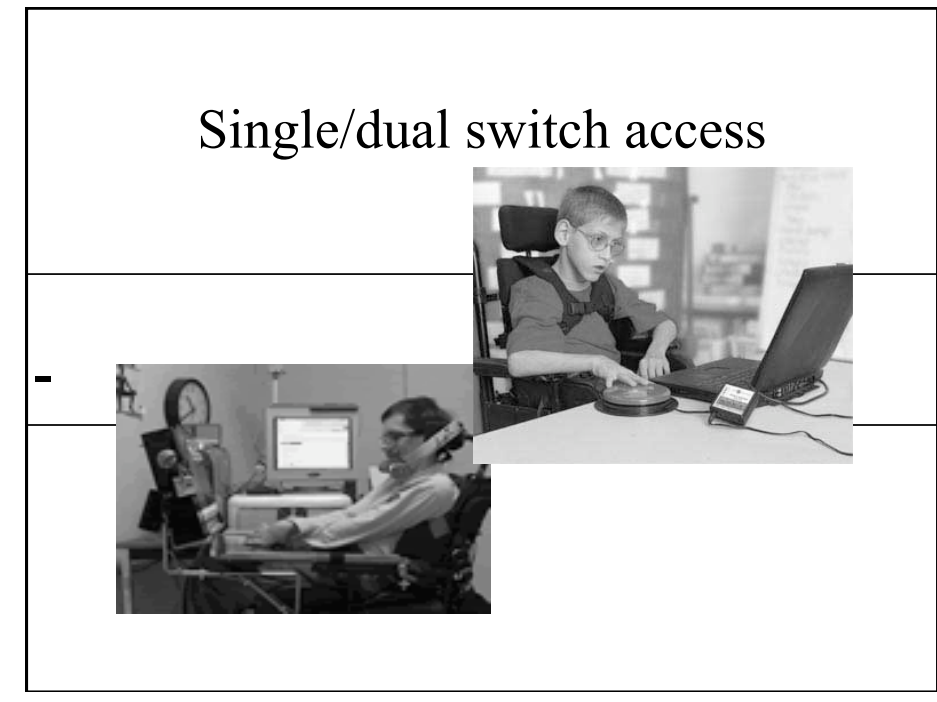

AAC staging for pALS and their families

(www.dukespeechandhearing.com)

STAGE 1. Normal Speech Processes

STAGE 2. Detectable Speech Disturbance

STAGE 3. Behavioral Modifications

STAGE 4. Augmentative Communication Use

STAGE 5. Loss of Useful Speech

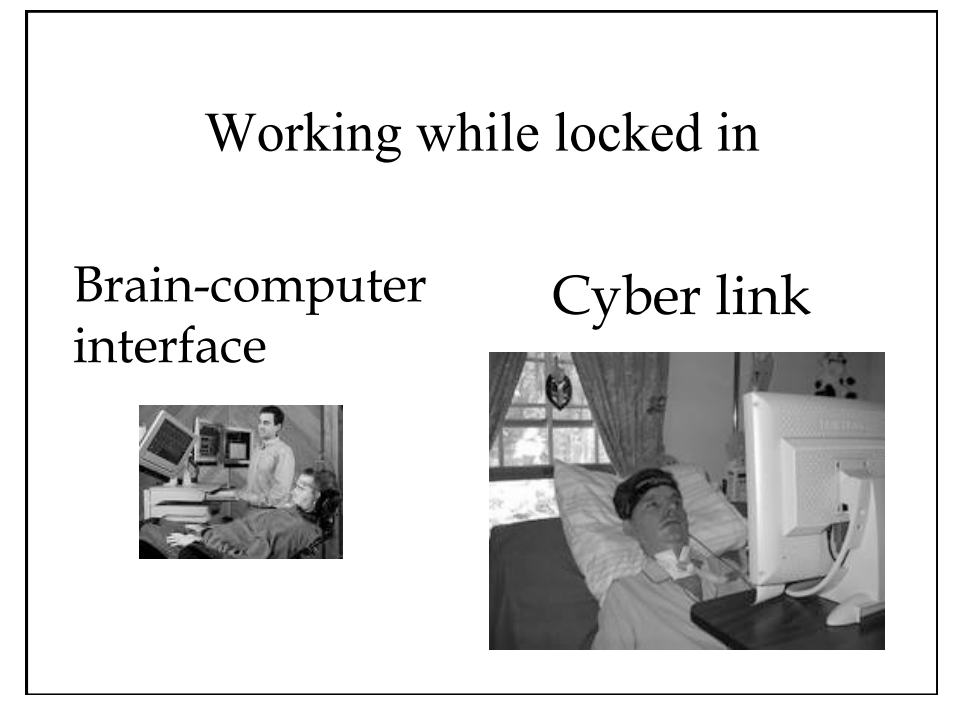

Stage 1 Normal Speech: Initial Consult, Education, Counseling

- Listen

- Begin to build trust and rapport

- Explain your general resources, why you are part of their intervention team

- Depending on person, may or may not bring up likelihood of speech loss at first visit

- Assure that resources exist to accommodate loss of communication if conversation goes there

- Baseline speech/lang eval, cognitive screen and speech sample if possible 
Stage 2 Detectable Disturbance:

\section{Education}

- Listen

- Explain what is happening

- Attempt to determine rate of speech change

- Speech/lang eval, cognitive screen and speech sample

- Augmentative resource education based on symptoms (dysarthria vs. low volume)

- Begin to sketch intervention plan to comprehensively address needs and maximize resources

\section{Stage 3 Behavior Modification: Basic Implementation}

- Listen

- Explain what is happening

- Attempt to determine rate of speech change

- Speech/lang eval, cognitive screen and speech sample

- Augmentative resource education and application of light strategies based on symptoms (dysarthria vs. low volume $=\mathrm{TX}$ or amplification, etc.)

- Continue to formulate intervention plan to comprehensively address needs and maximize resources

\begin{tabular}{|c|}
\hline $\begin{array}{c}\text { Stage 4:Augmentative } \\
\text { Communication }\end{array}$ \\
\hline 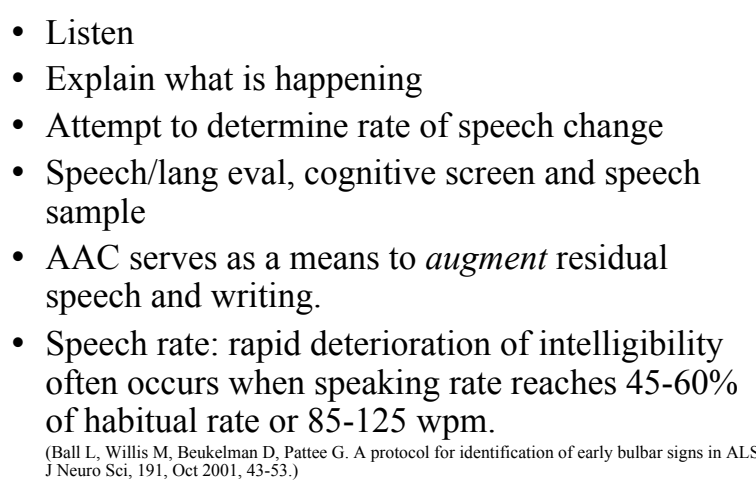 \\
\hline
\end{tabular}

\section{Stage 5: Alternative Communication}

- A person no longer has any use of functional speech; AAC is an alternative for their verbal communication.

- Include many techniques from no tech (vocalizations) to low tech (alphabet board) to high tech (SGDs and ECUs).

- Our role: integrate AAC into their daily lives at a pace suitable to their functional needs, environmental support and emotional capacity. 


\section{Why do we intervene?}

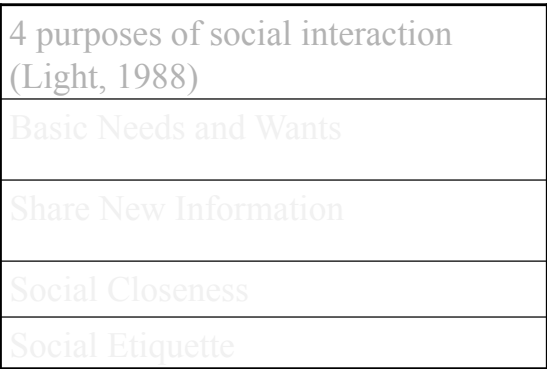

Fried-Oken M, Fox L, et al. Purposes offALS communicating with technology.

Augmentative and Alternative Communication. 2006

\section{Competencies Supporting AAC}

- Linguistic: What code used? What is knowledge of code? How will it be represented? How will it be learned?

- Operational: How does the technology work? Who will support it?

- Social: What are the rules of social intercourse? How does the AAC user characterize those rules?

- Strategic: How well does the AAC user comprehend the limitations of the system? How are those limitations dealt with?

\section{Social Purposes of Communication}

1. Expression of needs/wants.

- Regulates behavior of listener, content important, accuracy important, often rated as more critical by AAC practitioner and communication partners than users

2. Information transmission.

> Share information, content important, tend to be more novel messages - more difficult for AAC user

3. Social Closeness

Develop social bond, content less important, interaction quality important - good use of voice banking

4. Social Etiquette

> Fulfill conventions, predictable content (e.g. please and than you) - many systems pre-loaded with this, or voice banking

\section{How successful is AAC? Acceptance of AAC by pALS}

- In a sample of 50 pALS,

- 90\% accepted AAC technology immediately (no sig. diff by gender, spinal vs. bulbar ALS, or age.)

- $6 \%$ accepted AAC technology after some delay

- $4 \%$ rejected AAC technology (due to lack of support from family or recommendation from physician)

Ball L, Beukelman D, Pattee, G Acceptance of augmentative and alternative communication technology by persons with amyotrophic lateral sclerosis. Augmentative and Alternative 


\section{Clinical impressions}

- AAC use puts pALS (and other neurodegenerative Dx groups) in a "bilingual speaking situation"

- Most pALS are capable of learning to use AAC multi-modal system, adapt to motor access changes as needed

- But not without significant counseling and support using a participation-based approach

- No "one best way" to intervene - "optimal" a moving target

\section{Employment and AAC}

- Do pALS use AAC at work?

- pALS who can adapt jobs for text-generation remain employed longer

- pALS express satisfaction with employment and motivation to continue contributing in the workplace

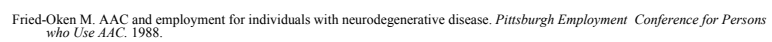

\section{Language Representation}

What is current AAC technology intervention?

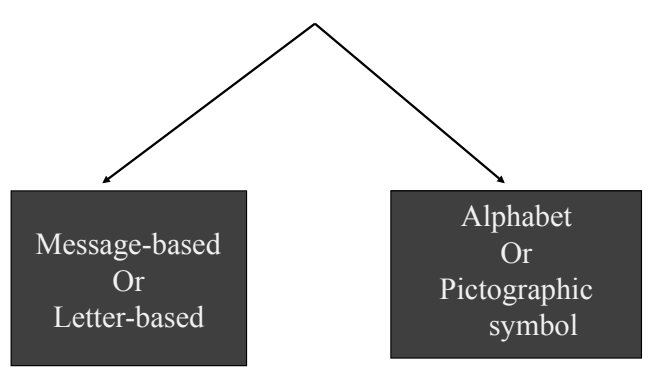


Rate Enhancement Techniques

- Quickfires by Dynavox

- Word and phrase prediction

- Visual Scene Displays

- Natural Language Processing with closed vocabulary sets

- RFID or some facsimile thereof, serverbased vocabulary?

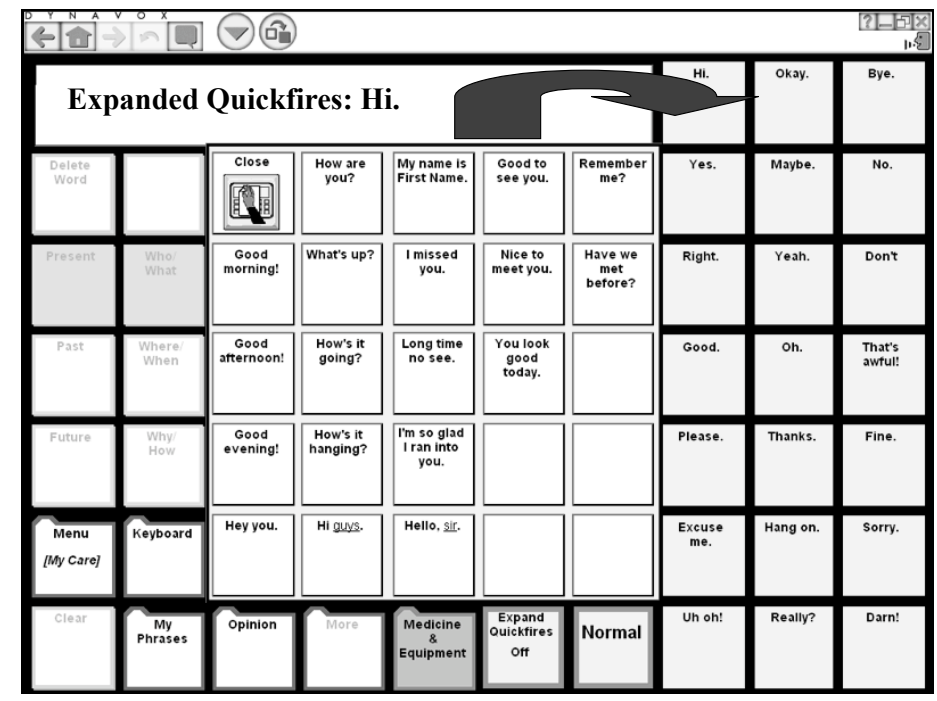

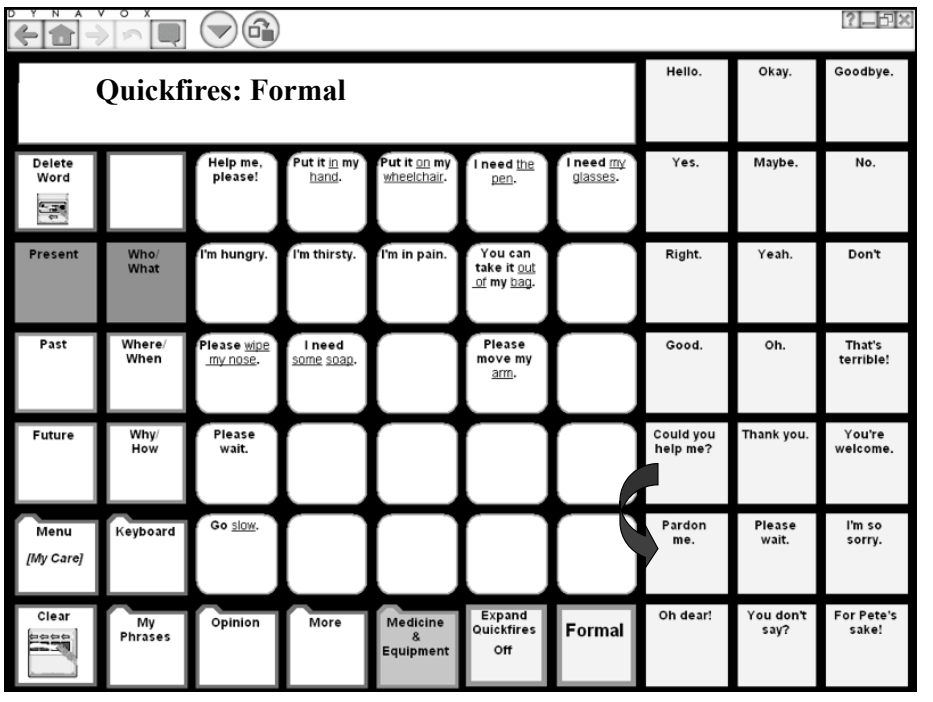

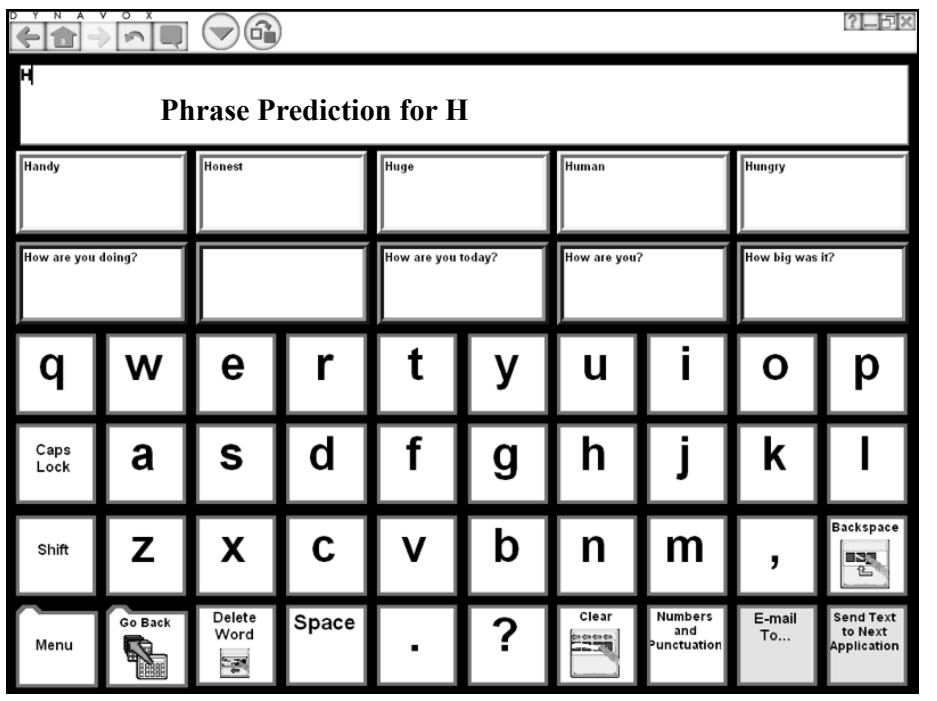



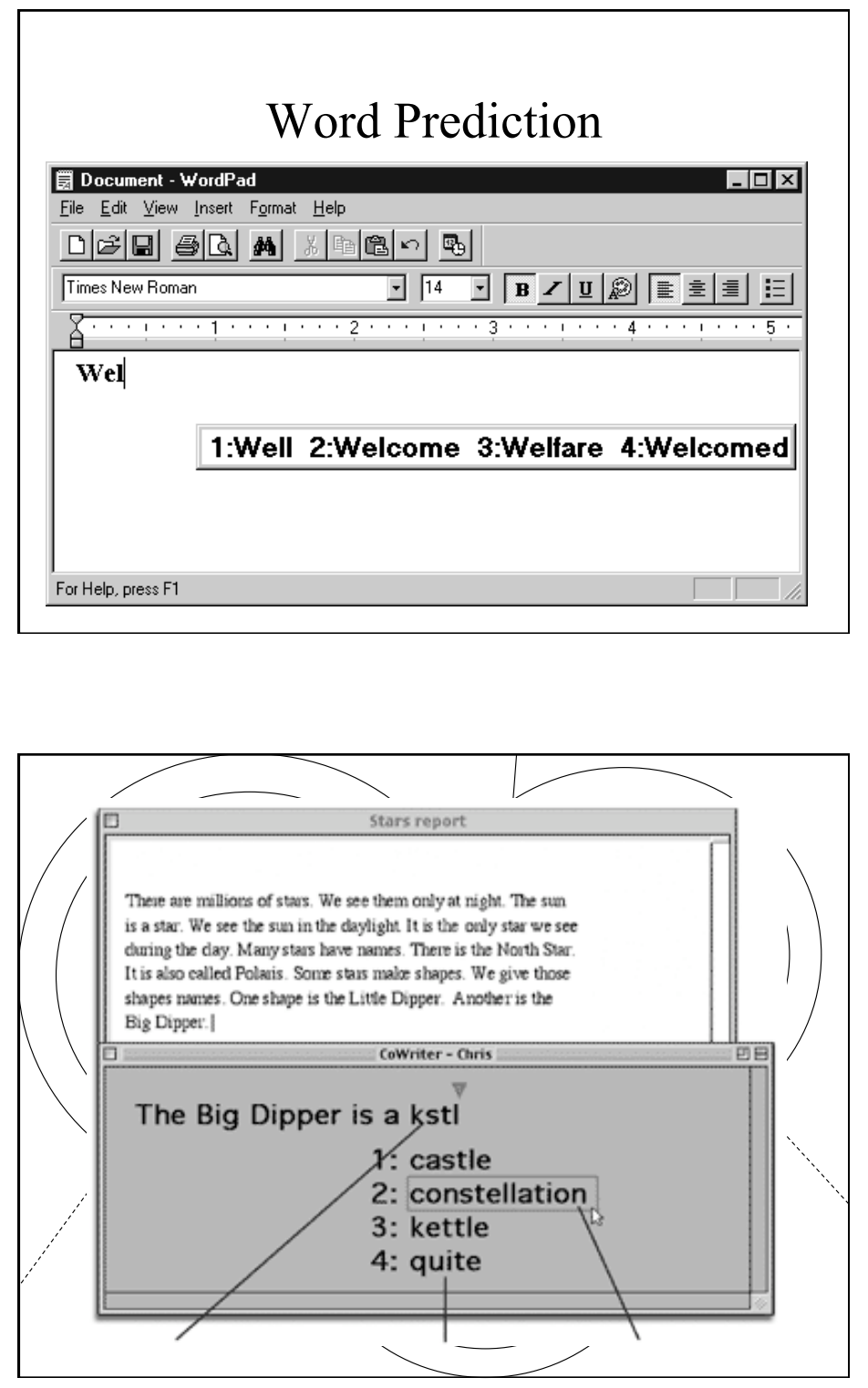

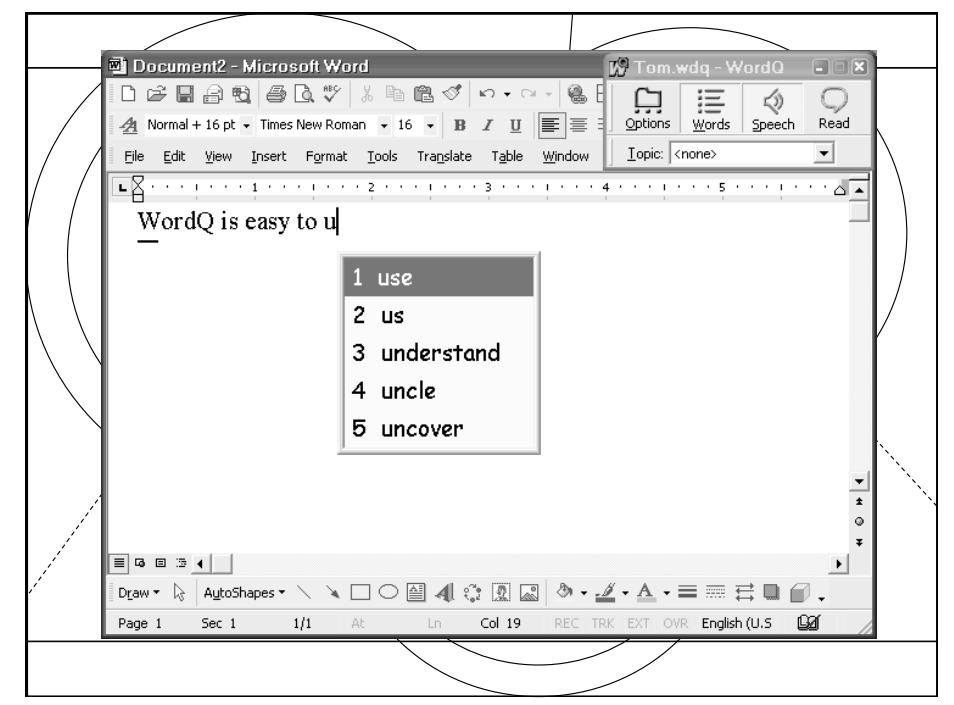

abbreviated expansions (macros)

- $\mathrm{AAC}=$ Augmentative and Alternative Communication

- $3 \mathrm{~S}=3$ spades

- $3 \mathrm{C}=3$ clubs

- $3 \mathrm{H}=3$ hearts

- $3 \mathrm{D}=3$ diamonds 


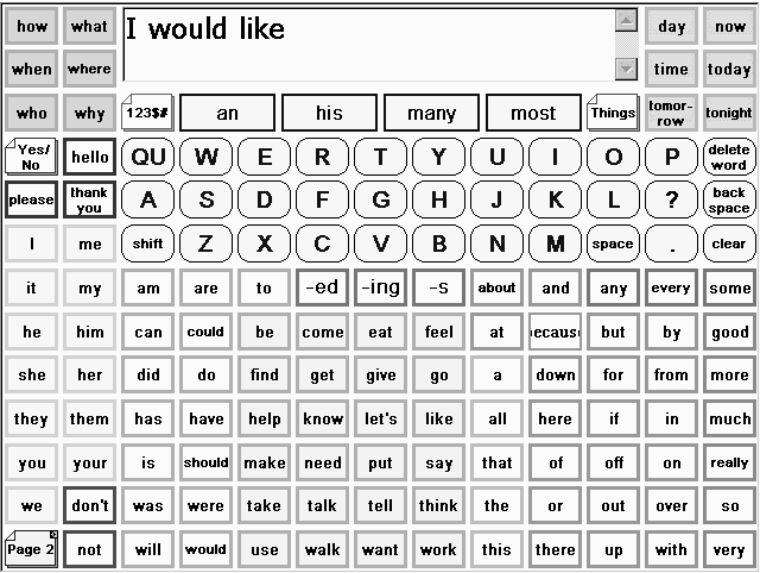

Visual Scene Displays: Support for storytelling

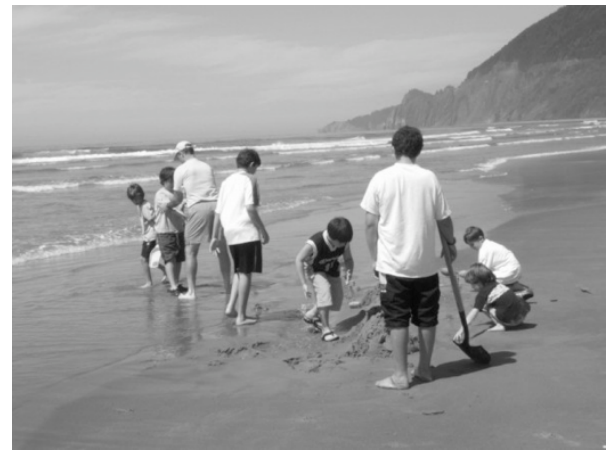

\section{Morse Code}

- 2 switch option

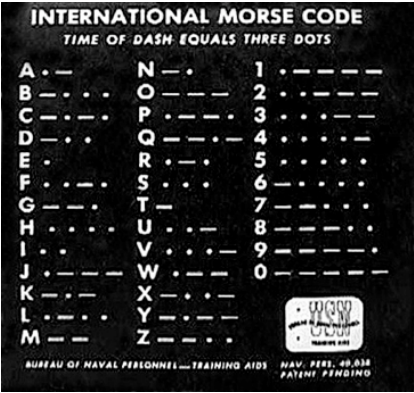

\section{Benefit of visual scene displays}

- Highly naturalistic organization of communication vocabulary

- Decreased memory load

- Less need to re-work system with cognitive decline

- Establish a shared communication space

- Serve as a platform for co-constructing messages

- Allow for integration with other types of communication supports 


\section{Contextually-based NLP}

- Access large vocabularies for specified topics

- Use in word or phrase prediction

- Use with location-specific or partnerspecific messages (e.g. messages related to preschool when talking with 3 y.o. grandson)

\section{Voice Banking}

- Allows communication in pALS' voice and intonation patterns to retain personality during nonspeaking condition "Yeah, right!"

- Reduces depersonalization of AAC

- Reduces feelings of loss of control, helplessness;

- Reduces anxiety and fear

- pALS takes active role in care

- Gives family a concrete way of assisting in care by choosing messages

Source: Costello, John. (2000). AAC Intervention in the Intensive Care Unit: The Children's
Hospital Boston Model. $A A C, 14: 144-153$.

\section{Output Mode}

- Voice banking

- Off-the-shelf speech synthesis

- Personalized speech synthesizer

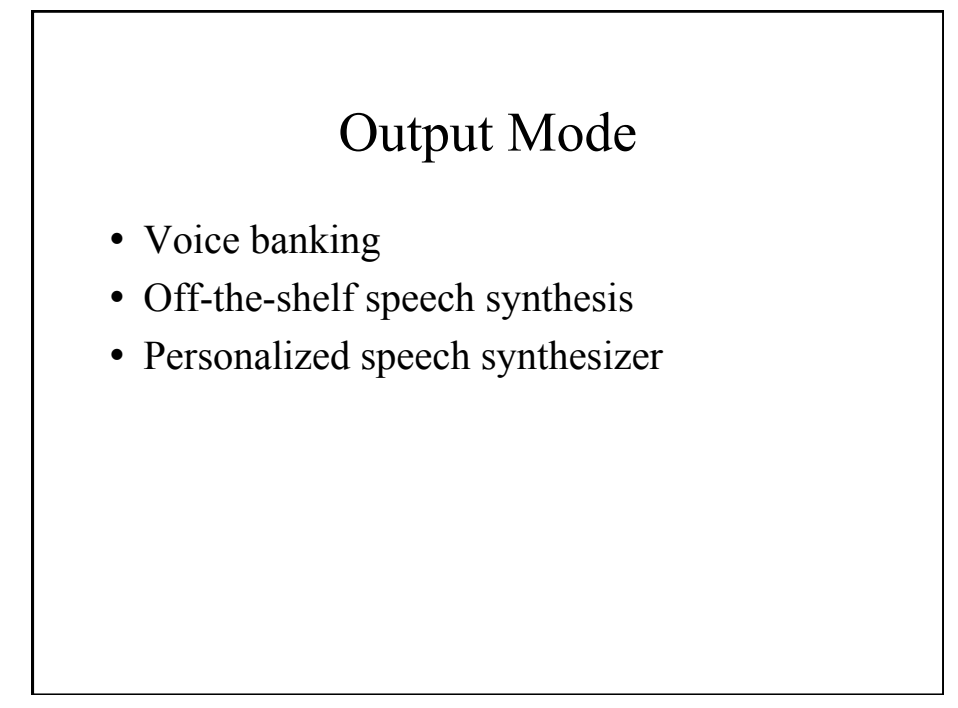

\section{Voice Banking Procedure}

- Before starting remind yourself to be sensitive to psychological demands of voice banking

- Be prepared to stop if too emotional

- Determine messages to be saved for later use

- Consider

- Personal, idiosyncratic messages

- Question words

- Purposes of communication

- Digital recording best option (http://audacity.sourceforge.net)

- Transfer to speech generating device later 


\section{Speech Synthesis}

- Quality of synthetic speech:

- Multilingual options for same SGDs

- As speech science advances, so does the quality of speech output.

- Synthetic vs. Concatenative

- Customized synthetic speech:

- The concept: Synthesize a voice based on the

parameters of an individual user.

- Record samples of user's voice and use as data for speech synthesis.

- http://www.modeltalker.com/

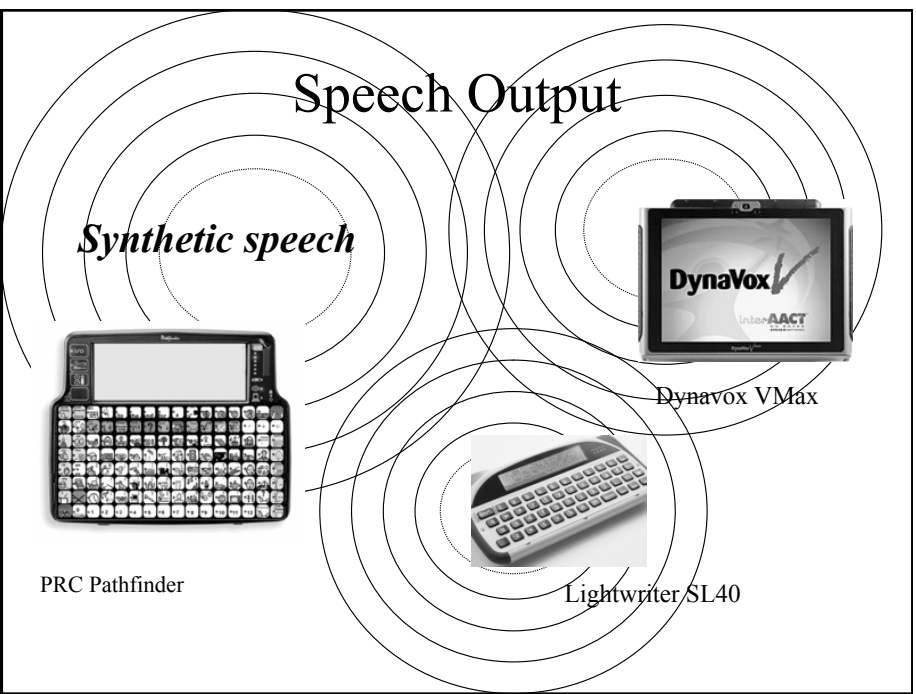

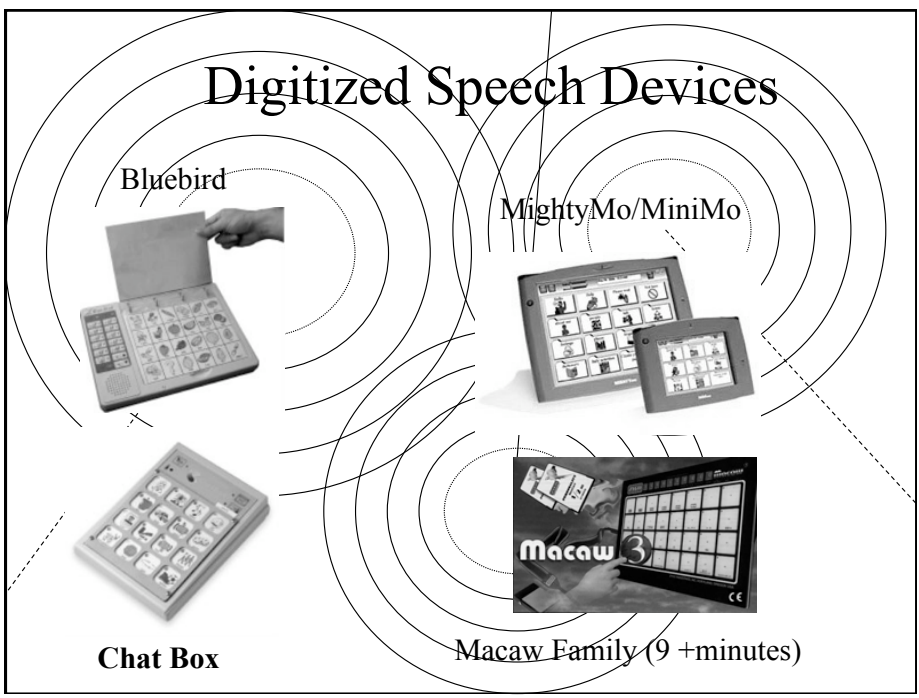

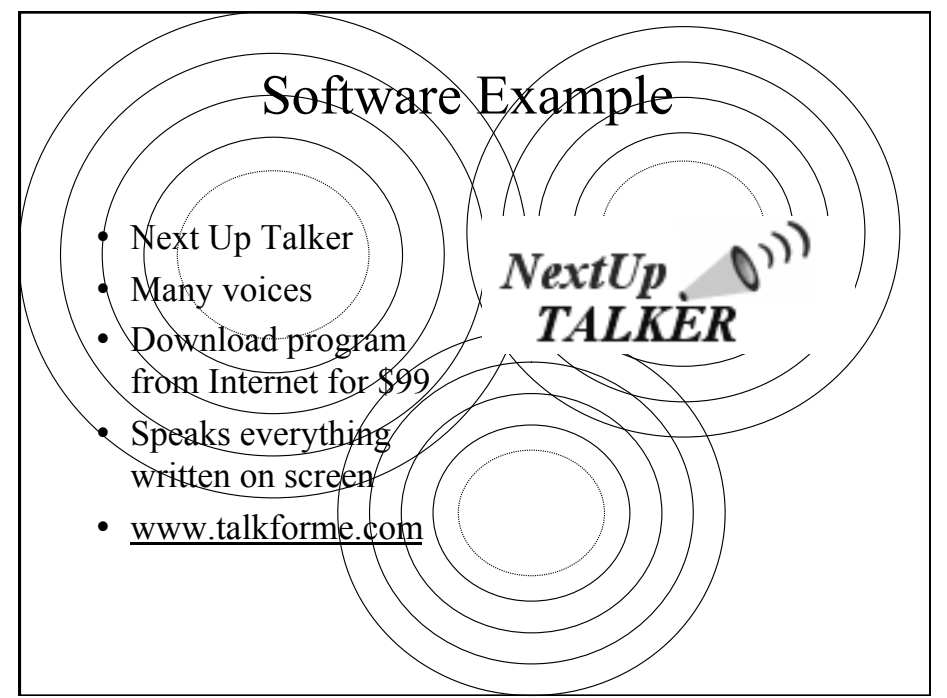




\section{Motor Access}

- Alternative access options

- Switches

- Eyegaze options

- BCI (brain-computer interfaces) options

- Always consult an OT/PT with ALS experience

\section{Positioning}

- Attempt to achieve symmetry

- While placing a switch imagine what it would be like to use it.

- Stabilize trunk and extremities. Don't ask someone to extend their arm into space or crane their neck.

- Minimize residual movement (usually by providing good support).

- Allow resting position.

\section{Positioning}

- Majority of time in power chair = huge potential for chronic pain, injury, terrible support for access, high fatigue, gross underestimation of potential.

- Variations in tone throughout body (high in some regions, low in others) requires extensive assessment and support.

- Reflex patterns can be controlled to a degree via positioning/support.

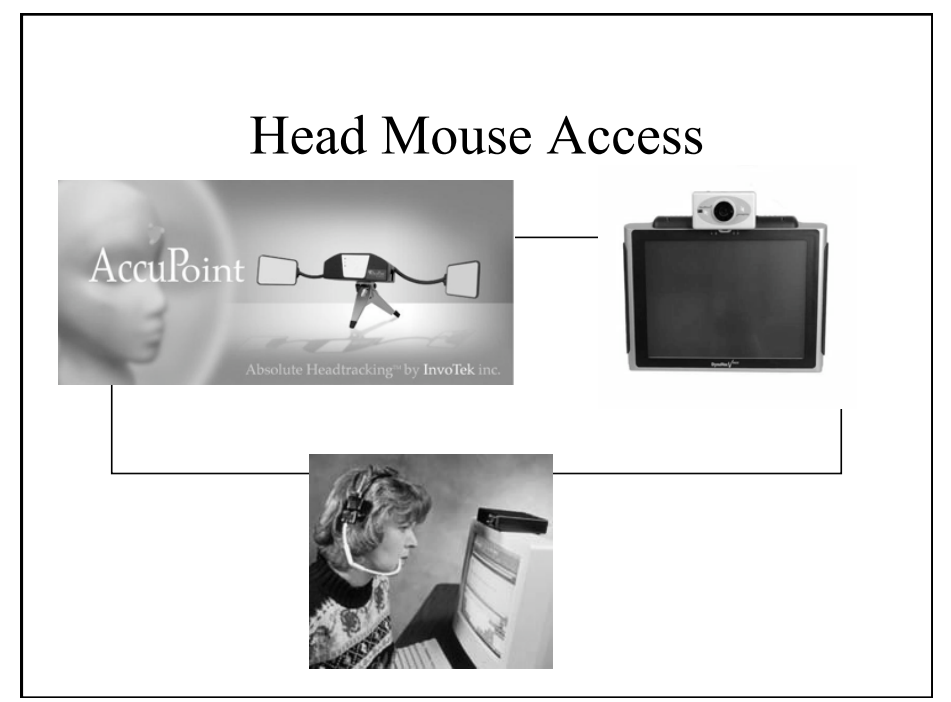




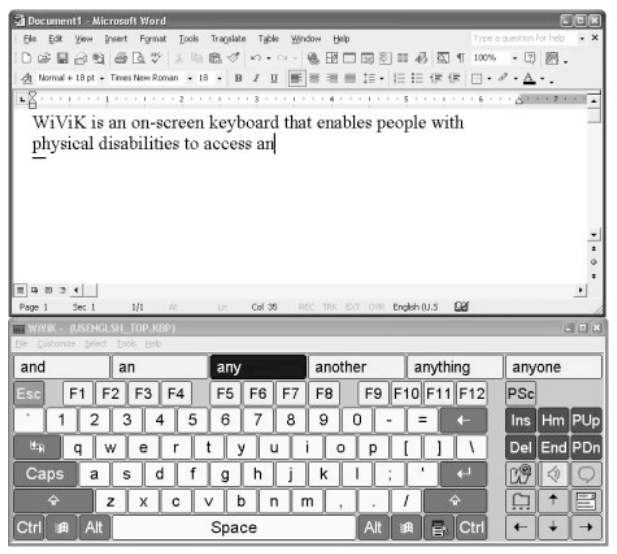

Free: Click n type; e-triloquist; Microsoft accessibility suite

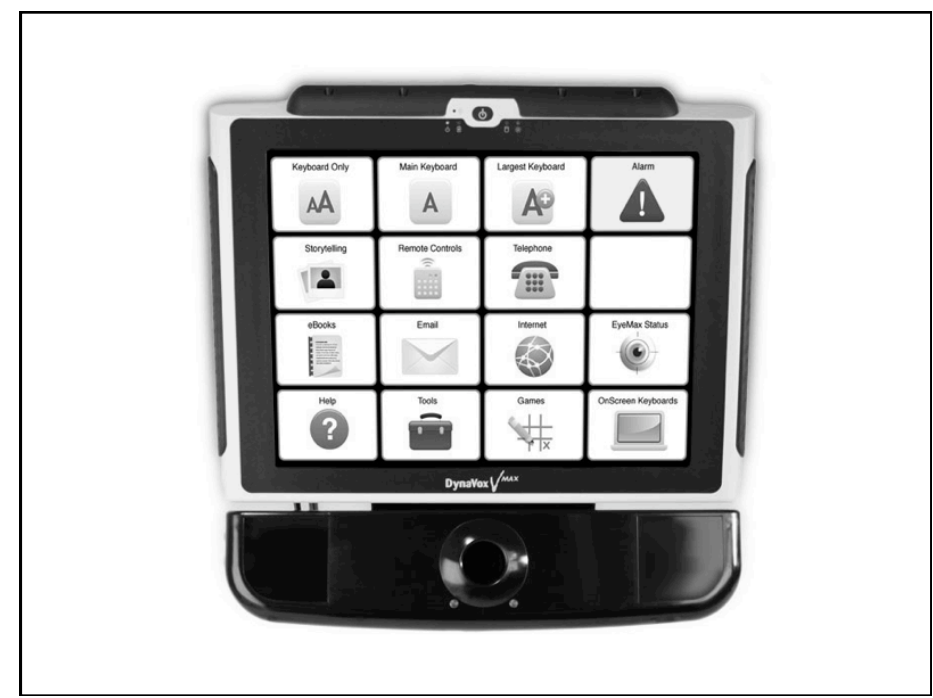

Eye gaze as input www.cogain.org

Catalogue of currently available eye trackers for interactive applications

Alea Technologies Simbh

$\frac{\text { DynaVox Technologics }}{\text { EyeMax System }}$

$\frac{\text { EEve Response Technologice }}{\text { ERICA }}$

$\frac{\text { Everect Dipital Systems }}{\text { Evecreht }}$

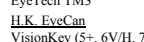

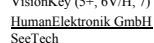

$\frac{L C \text { Technologics }}{\text { The Exyeger Co }}$

The Eyegaze Con
Metrovision
VISIOBOARD

Oopootunity Foundatanof A Americ

PRC Prennke Romich Company)

TechnoWorks CO.LTT

TE-9100 Nursing System for Enhancing Patients' Self-suppor

$\frac{\text { Tobii Technology }}{\text { Tobii C8, C12, CEyc, MyTobbii P10, D10 }}$

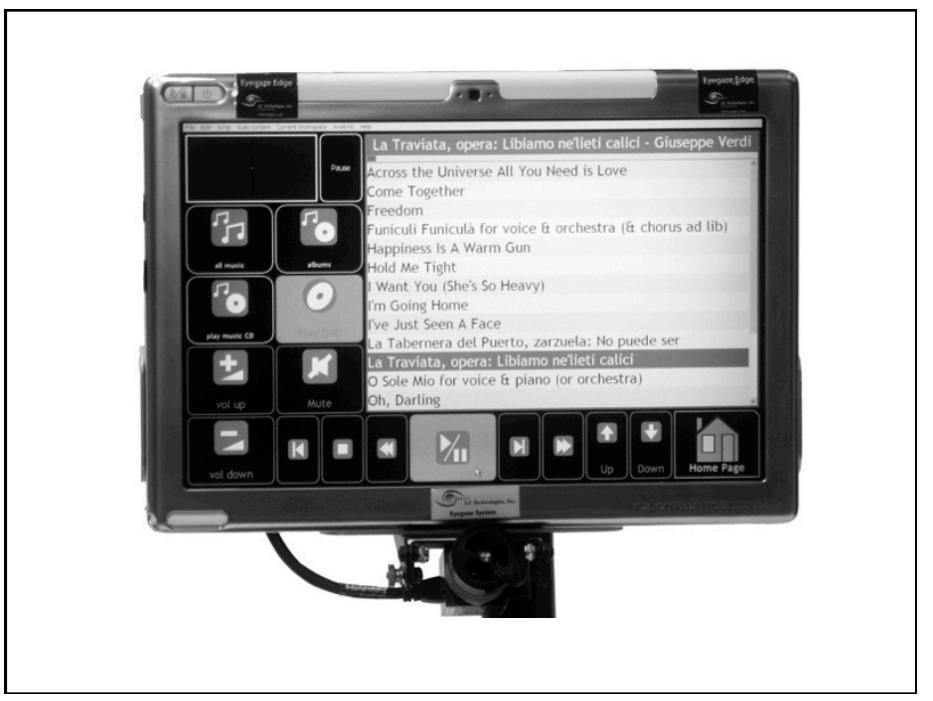




\section{Clinical Application...}

- AAC Paths will vary due to:

- Rough ALS type

- Bulbar onset

- Limb onset

- Presence of FTD

- Patient specific variables

- Environmental support

- Access to external support (clinic, reps, etc.)

\section{What is PPA?}

1. A degenerative language disorder.

2. A language disorder that does not easily fit into the classical aphasia typology.

3. A syndrome, often followed by cognitive decline, that has been described with 3 variants.

\section{Primary Progressive Aphasia}

\section{Diagnostic Criteria for PPA}

Mesulam, M. Annals of Neurology, 49 (4), April, 2001

1. Insidious onset and gradual 2. ADL limitations attributable to loss of word finding, object- language impairment, for at least naming or word-

2 yrs after onset;

comprehension skills in

spontaneous conversation; 4. Absence of significant apathy, disinhibition, forgetfulness for recent events, visuospatial

3. Intact premorbid language impairment, visual recognition skills;

dysfunction within initial 2 yrs of L impairment; 


\section{Diagnostic Criteria for PPA}

Mesulam, M. Annals of Neurology, 49 (4), April, 2001

5. Acalculia \& ideomotor apraxia may be present in first 2 yrs.

6. Other domains possibly affected during 2 yrs, bu language most impaired function.

7. Absence of specific causes (i.e., stroke, tumor, infection,

metabolic disorder) on neuroimaging.

\section{Diagnostic Characteristics}

- Age of onset 40-75 years old, mean onset age of 60 years.

- Preponderance of male patients - 2:1 ratio

- Roughly 50\% with genetic component

\section{3 variants of PPA} may overlap with

- Alzheimer's disease

- Frontotemporal dementia

- Corticobasal degeneration

- Dementia-lacking-distinctive-histology (DLDH)

- CJD

- ALS

- ACD (Asymmetric cortical degeneration; Caselli, 1995)

- Pick's disease

Kertesz \& Munoz, Amer. J. of Alzheimer’s Disease. (2002), 17(1).

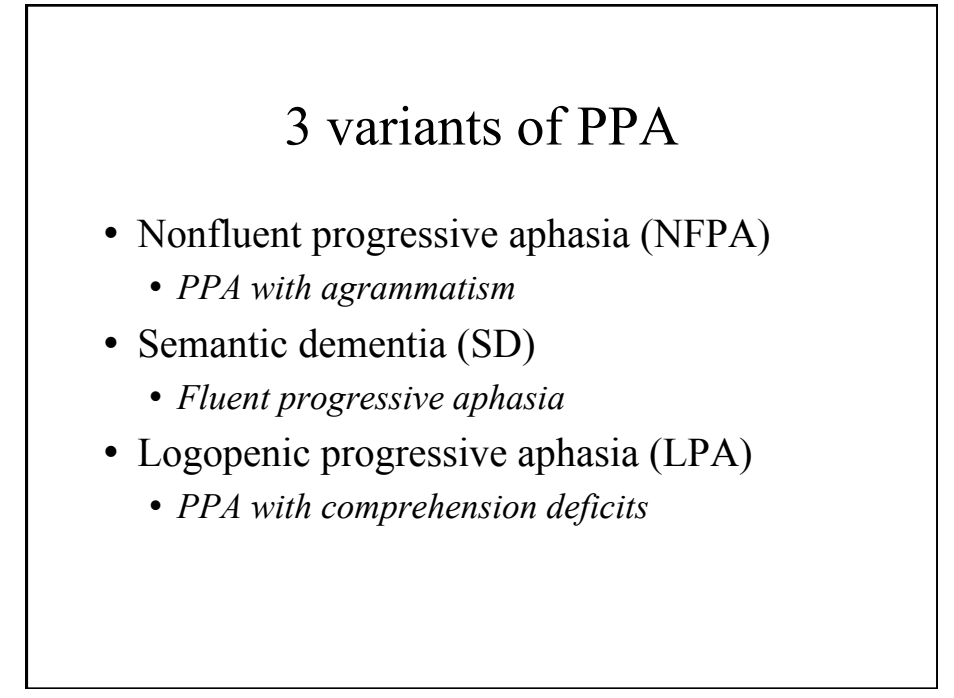




\section{NFPA: nonfluent progressive aphasia}

(most common type of PPA in an AAC clinic)

- Anomia or "trouble thinking of or remembering specific words when talking or writing".

- Initial "empty" speech with preserved prosody and fluency but little information.

- Slow, hesitant and labored speech frequently punctuated by long pauses and filler words, early symptoms of agrammatism.

- Simplification (generic words for specific concept)

- Circumlocutions

- Substitution by fillers ("thing," "Whachamacallit")

- Phonemic paraphasias

- Marked increase in speech errors, early symptoms of a progressive apraxia of speech.

- Relatively preserved single-word comprehension with later

difficulty comprehending complex syntactic structures.

- Stronger oral reading that generative language skills.

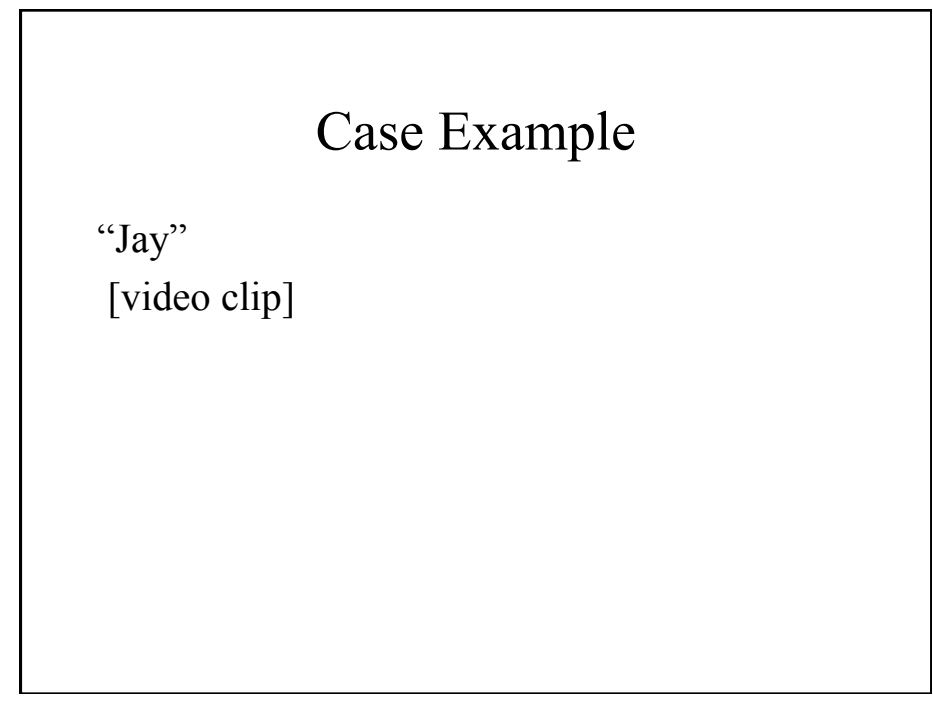

\section{Progression of disease varies}

- Yes/No confusion for responses

- Apraxia of Speech

- Agrammatism $\rightarrow$ Mutism

- Written language generation often mimics spoken language generation

\section{Semantic Dementia (SD)}

- Fluent, grammatical speech;

- Confrontation naming deficits (often word knowledge can be accessed through visuoperceptual route)

- Surface dyslexia (written word does not cue lexicon, auditory does)

- Deficits in word comprehension (2-way naming problems) "In time, even the most common words fail to be decoded and the comprehension of conversation becomes impossible, although visual recognition of objects and faces remains relatively preserved" (Mesulum, 2001)

- Later connected speech includes neologisms and semantic paraphasias 


\section{Case Example}

- "Deb"

- Excellent Comprehension

- Word Salad

- Marginally aware that she is serving up as large a helping of word salad as she is

- Confusions increasing, no longer able to handle phone calls and independent shopping, etc.

\section{Logopenic progressive aphasia} (LPA)

- Repetition and comprehension impaired for sentences but preserved for single words

- Naming moderately affected

- Severely impaired in digit, letter, and word span tasks

- Pointing does not improve performance

- No influence of word length and do not show the normal phonological similarity effects

- Atrophy or decreased blood flow consistently found in the posterior portion of the left superior and middle temporal gyri and inferior parietal

lobule (Gorno-Tempini, M.L., et al., Neurology, 2008)

\section{Case Example}

- "Doug"

- Virtually no verbalizations beyond 3-4 perseverative phrases ("I'm okay" or "I love you")

- Decent naming ability, picture presentation

- Terrible performance when picture board presented - semantic linking only

Stages of Intervention during the Neurodegenerative Language Process:

\section{NFPA}

I. No noticeable interference with generative language but some word finding problems;

II. Detectable language lapses with hesitations and dysfluencies;

III. Reduction in language use leading to behavioral strategies and introduction of low tech AAC (circumlocutions; paraphasias; simplification; agrammatism)

IV. Use of AAC tools and other techniques;

V. No functional language. 


\section{Communication Treatment Goals}

- \#1: To compensate for progression of language loss (NOT stimulate the language system to regain skills).

- \#2: To begin compensatory treatment as soon as possible. Be proactive so patient can learn to use communication strategies and tools.

- \#3: To include primary communication partners in all aspects of training, with outreach to multiple partners.

\section{The Treatment Challenges:}

1. To put the patient's residual lexicon visually in front so that the patient can participate in daily activities as language skills decline.

2. To begin soon enough to allow learning of this approach.

3. To engineer the environment to support successful communication.

4. To teach the communication partner that functional communication will be partner driven - this often upside down for many couples.

\section{Low tech tools}

- Customized communication boards

- Customized brag books

- Remnant bags/boxes

- Single message devices

- Talking photo albums

- Dry erase board

- Dynamic display devices with customized messages:

- Dynavox V or M3, or Express

- Words+ Say It Sam Tablet SM1

\section{High tech tools}

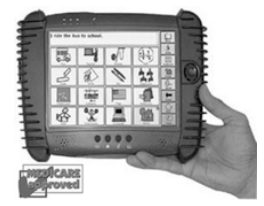




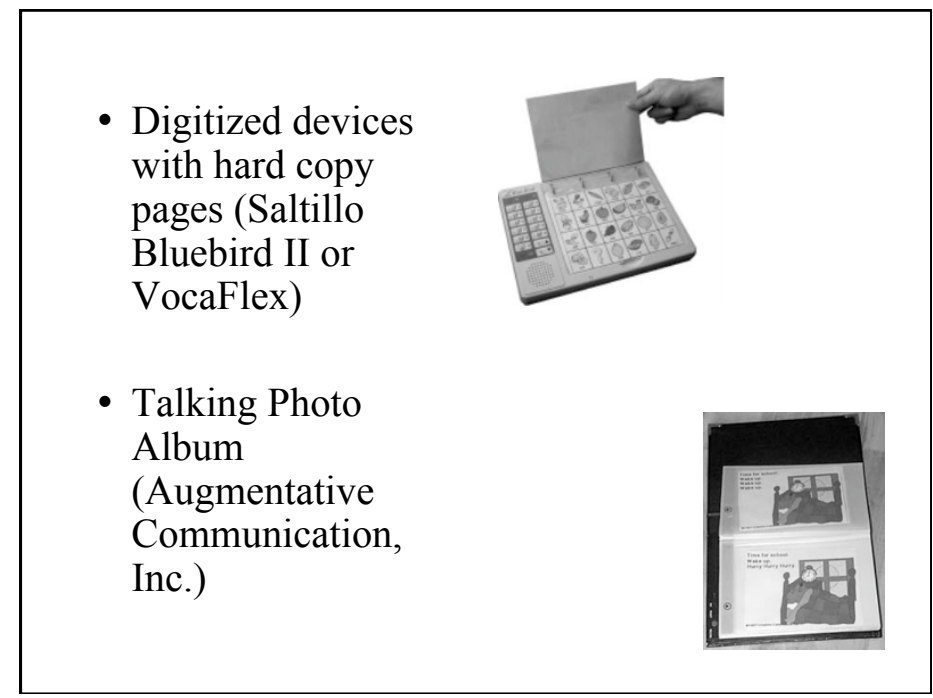

\section{Partner training is an essential component of AAC for persons with PPA.}

$>$ To tailor intervention and compensatory techniques to specific functional needs (PPA type)

$>$ To identify vocabulary for external lexicon.

$>$ To support use of tools in familiar communication settings.

$>$ To identify new opportunities for communication with tools.

$>$ To offer or confirm choices.

$>$ To initiate conversation during late stages of PPA.

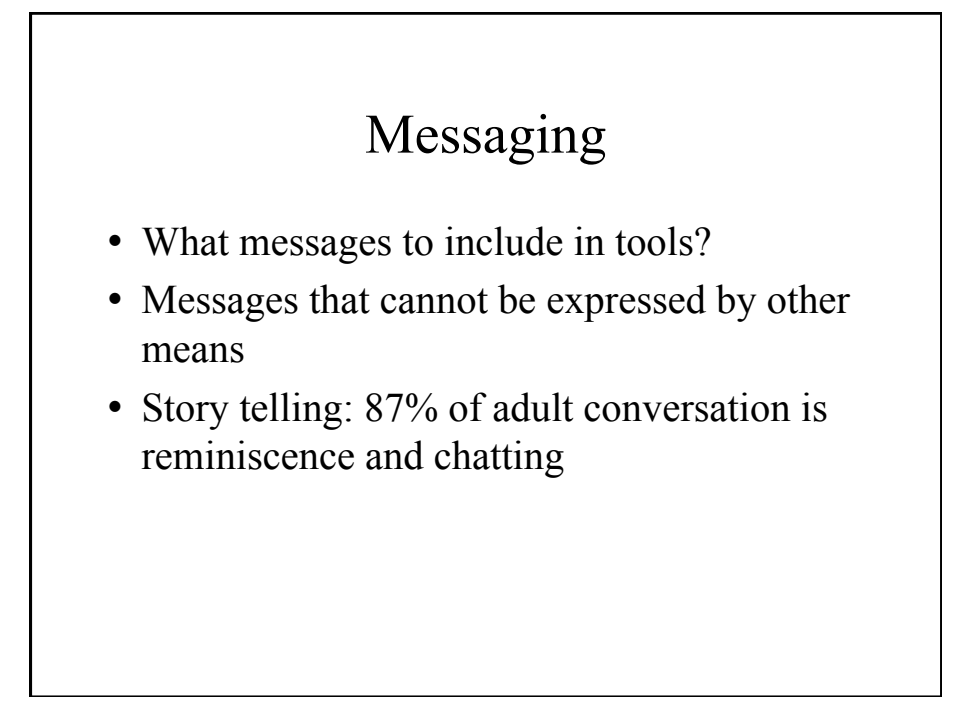

Rogers, MA \& Alarcon, NB. (1998). Dissolution of spoken

language in primary progressive aphasia. Aphasiology.

\begin{tabular}{|l|l|}
\hline $\begin{array}{l}\text { Impairment } \\
1993->1997\end{array}$ & $\begin{array}{l}\text { Intervention } \\
\text { Unassisted -> Assisted }\end{array}$ \\
\hline & \\
& \\
& \\
& \\
\hline
\end{tabular}




\section{Early Stage Intervention}

- Learn about the patient and their primary communication partners $(\mathrm{Hx}$, interests, family, ADLs, travel, etc.)

- Integrally involve the patient in constructing "memory" booklets, word lists, hierarchy of difficult situations - always evolving

- All practice should occur with the primary communication partner for future success

- More now $=$ more later

\section{Late Stage Intervention}

- Will likely scale back longer, more complex communication books, lists, etc.

- Stress daily routines, procedural memory for enjoyable activities

- Constantly monitor communication partner's ability to facilitate use of tools

- Watch for further changes in comprehension, ability to use other modes of output, etc.

\section{Mid-Stage Intervention}

- Capitalize on early learning and practice with communication partner to bulk up communication books

- Be mindful of text vs. pictures, combination, visual scene display, etc.

- Be mindful of comprehension difficulties (auditory, visual, orthographic)

- Use other output modes when possible (e.g. drawing, writing)

\section{www.brain.northwestern.edu/PPA*}

- PPA Newsletters from 1996 (on line)

- Join mailing lists

- Connect to PPA databases

- Clinician search and database

- PPA literature database

- Question and answer archive

- PPA Family Support Group

- *maintained by The Cognitive Neurology \& Alzheimer's Disease Center at Northwestern University, Dr. M. Mesulam 


\section{Alzheimer's Disease}
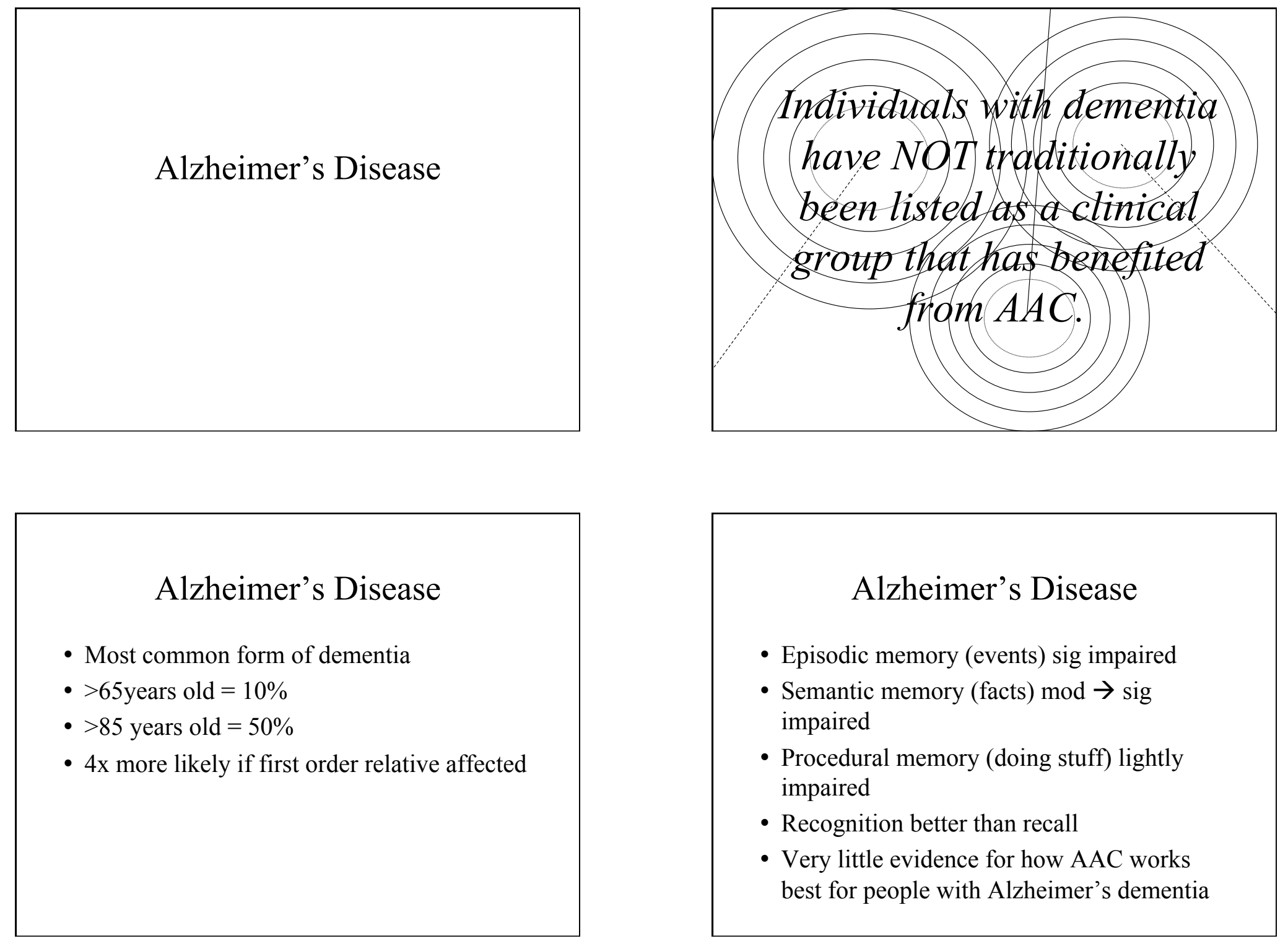

\section{Alzheimer's Disease}

- Episodic memory (events) sig impaired

- Semantic memory (facts) mod $\rightarrow$ sig impaired

- Procedural memory (doing stuff) lightly impaired

- Recognition better than recall

- Very little evidence for how AAC works best for people with Alzheimer's dementia 

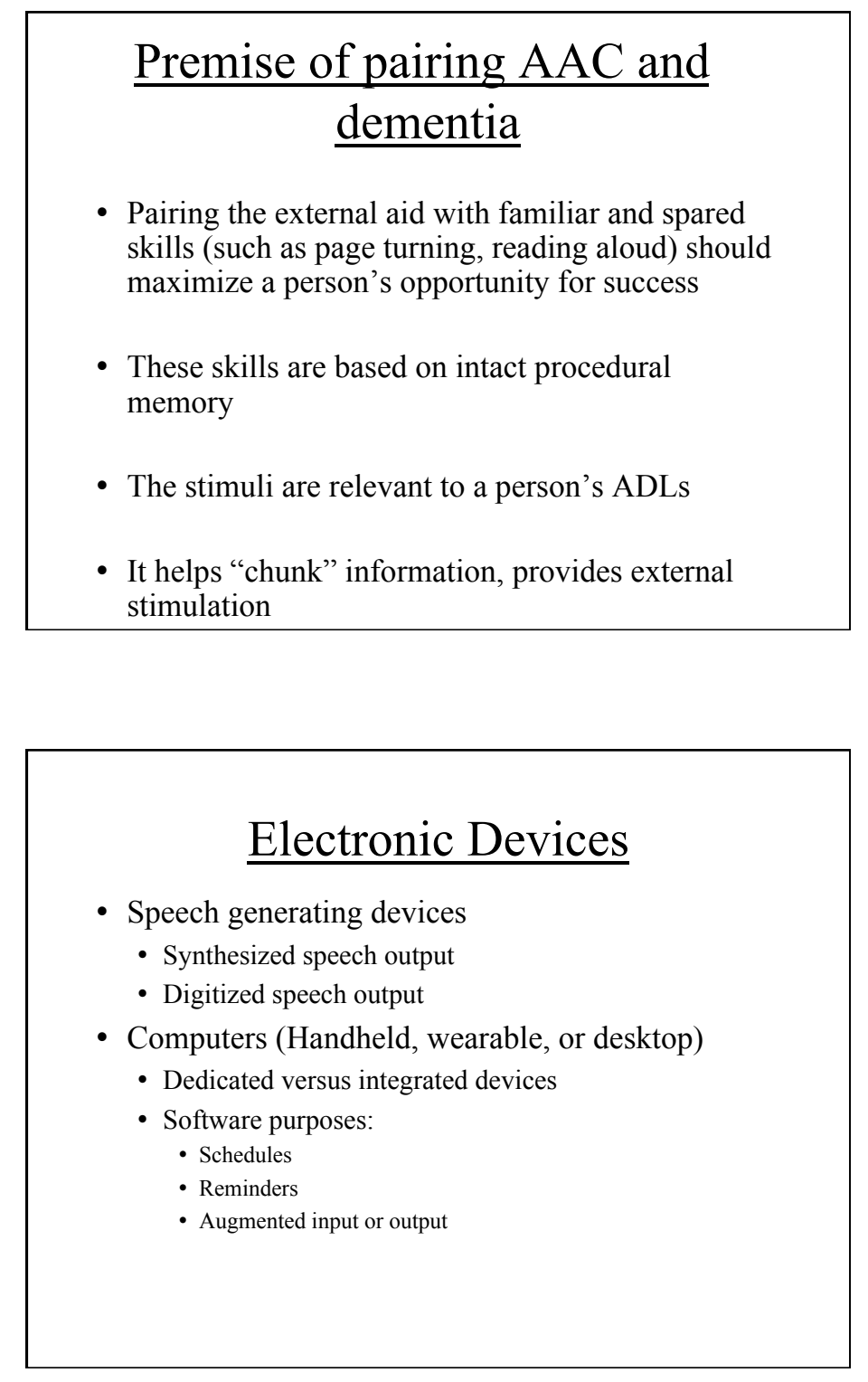
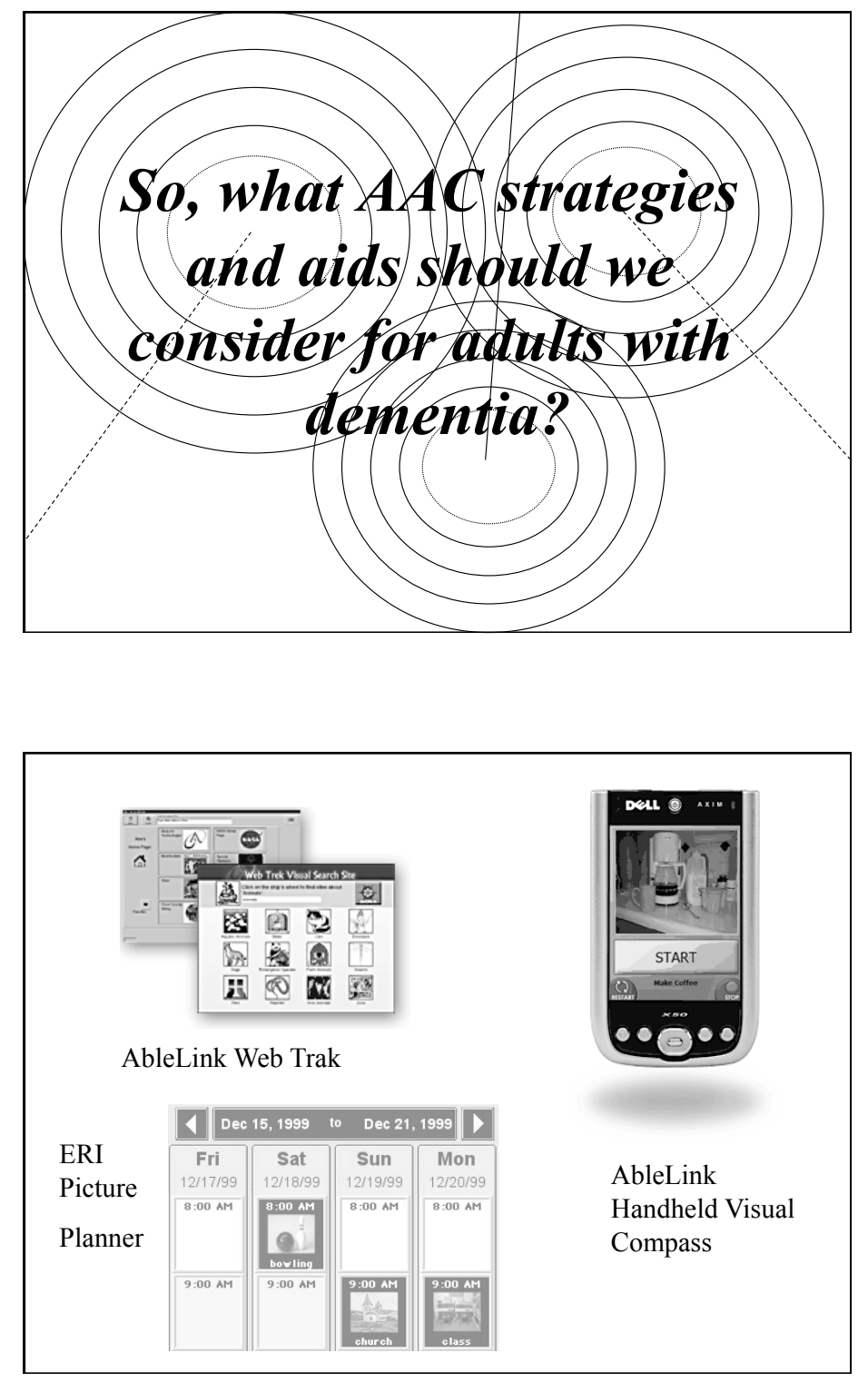


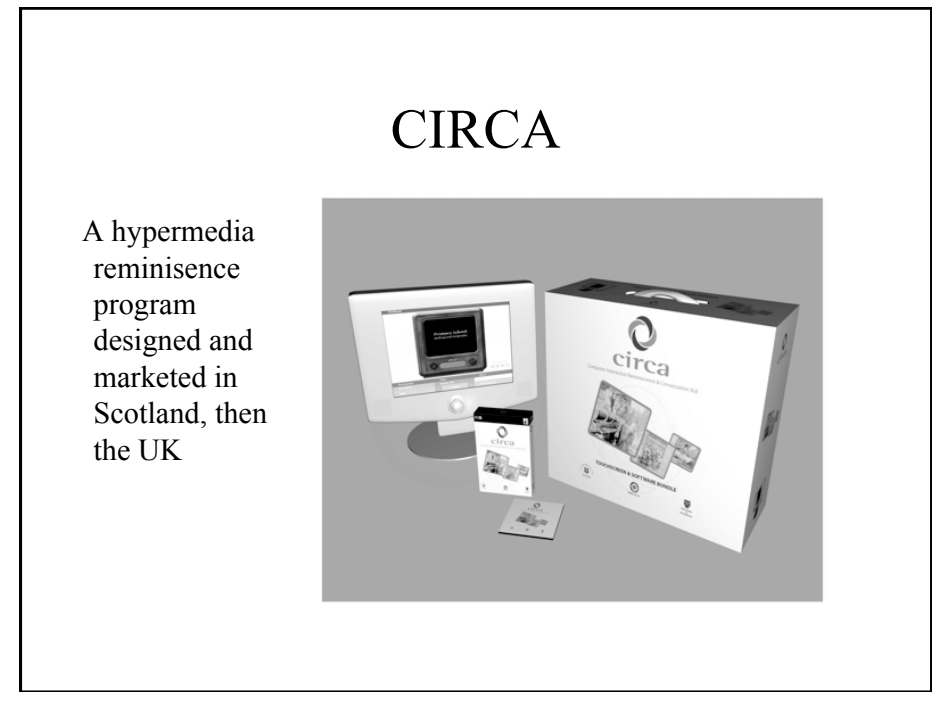

\section{External memory aids:}

- Notebooks

- cards

- communication boards

- calendars

- signs

- timers

- labels

- color codes

- tangible visual symbols
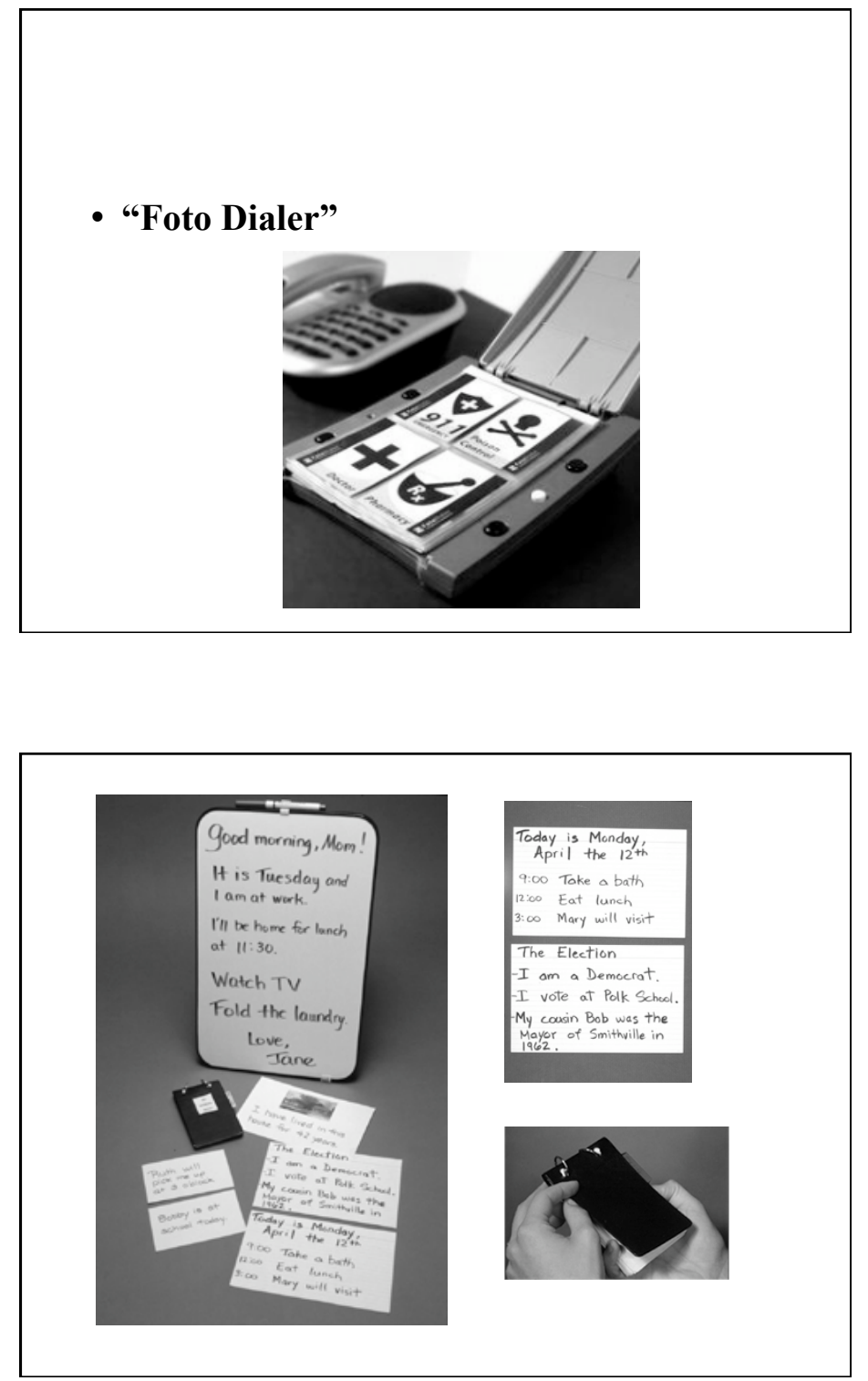


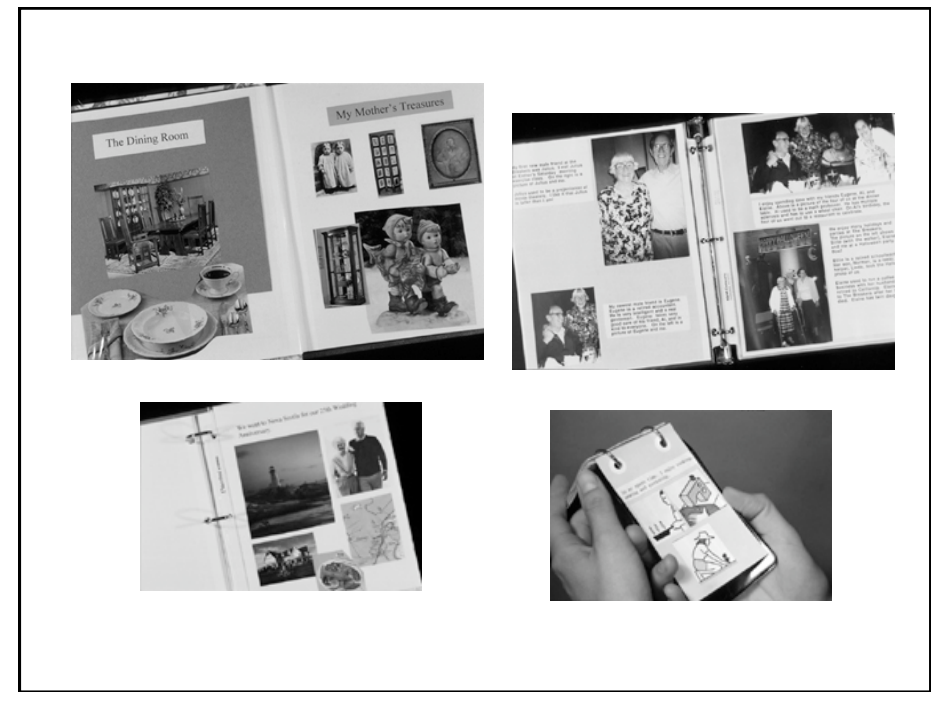

\section{$\underline{\text { Results }}$}

- Increased the frequency of factual information

- Decreased the rate of ambiguous, perseverative, erroneous, or unintelligible utterances

- Increased the conversational responsibility (turn taking) of person with dementia

- Increased the number of on-topic statements during a conversation
Bourgeois research (1991-1994)

- Made individualized memory wallets or cards

- Persons with mild AD

- Measured outcomes of conversations between trained caregivers (spouse, adult child, day staff)

- Wallets: Pictures and words for 3 topics:

- Family names

- Biographical information

- Daily schedules

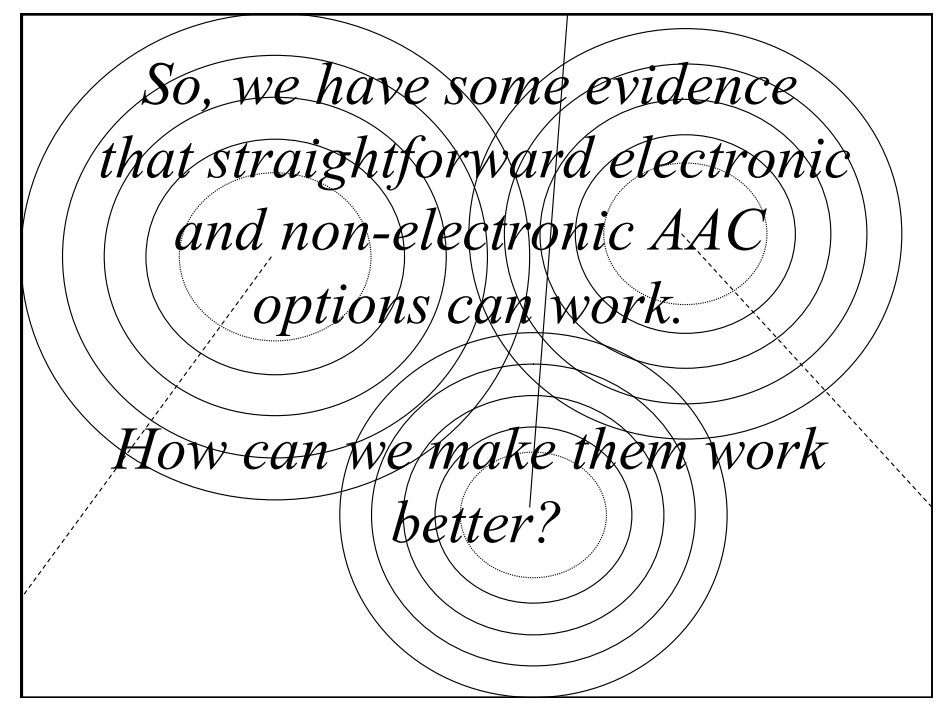




\section{3 things to consider for each aid:}

1. The messages or language in the aid

2. How those messages are presented

3. The output, or result, of selecting a message from the aid

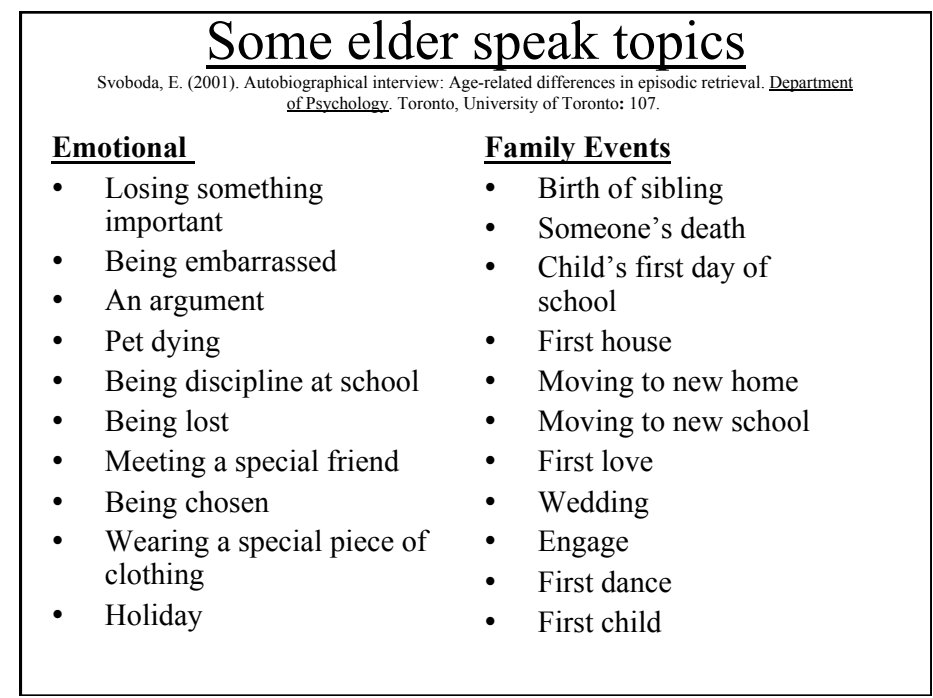

\section{What messages should be chosen?}

- Autobiographical memories might be accessible

- Messages that affect the environment might be more meaningful

- Documented message topics from the language of elders

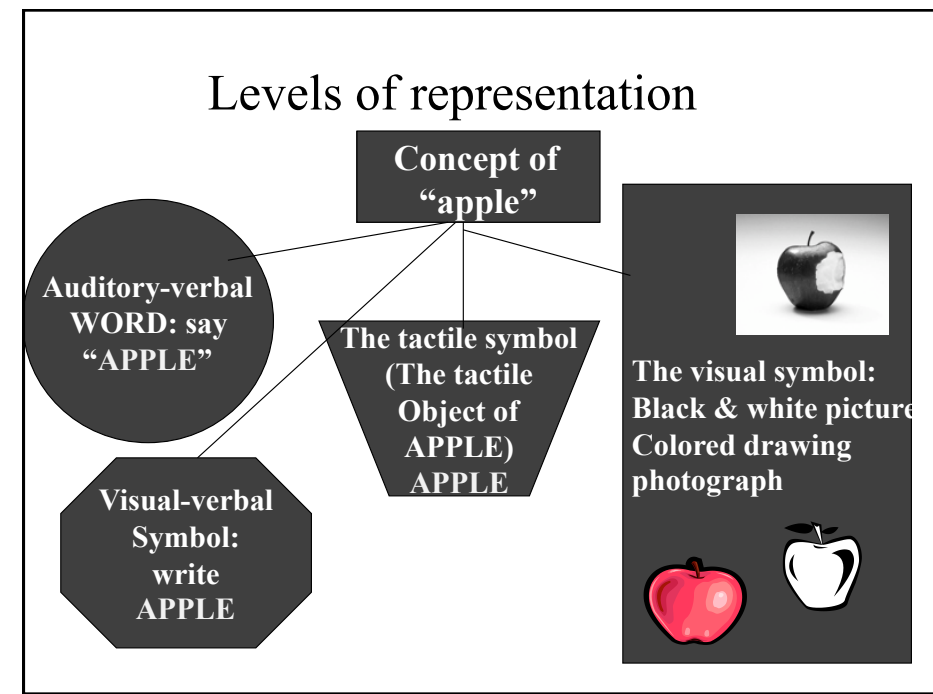




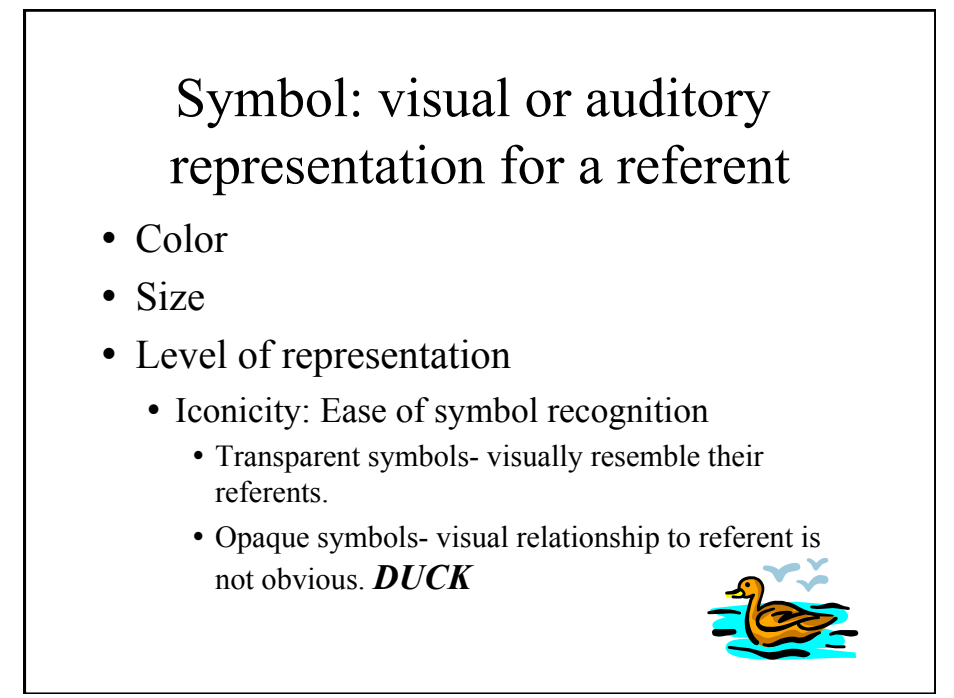

\section{$\underline{\mathrm{AD} A A C}$ research question:}

- Do AAC tools improve the quantity or quality of conversation by individuals with moderate Alzheimer's disease?
What will be the result of symbol selection?

- Communication partner validates message

- Electronic voice output (if used) labels the symbol

\section{Specific Aims}

- 1. To compare the effects of different input modes in an AAC device on conversational skills of persons with moderate AD.

- Print alone

- Print + photographs

- Print + 3-dimensional miniature objects

- Photographs alone

- 3-dimensional miniature objects alone

- Control condition (no board). 
- 2. To compare the effects of output mode in an AAC device on the conversational skills of persons with moderate AD.

- Digitized speech output

- No speech output

\section{Lena's cooking board (3-D only)}

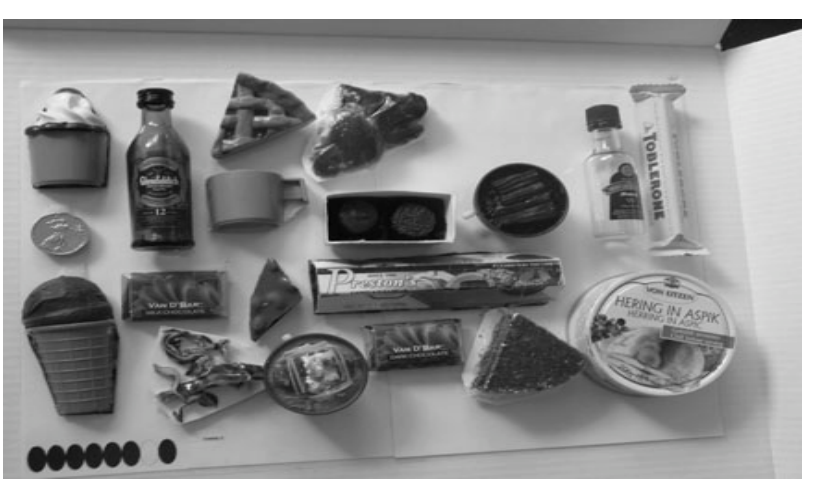

Lena's cooking board (2-D only)

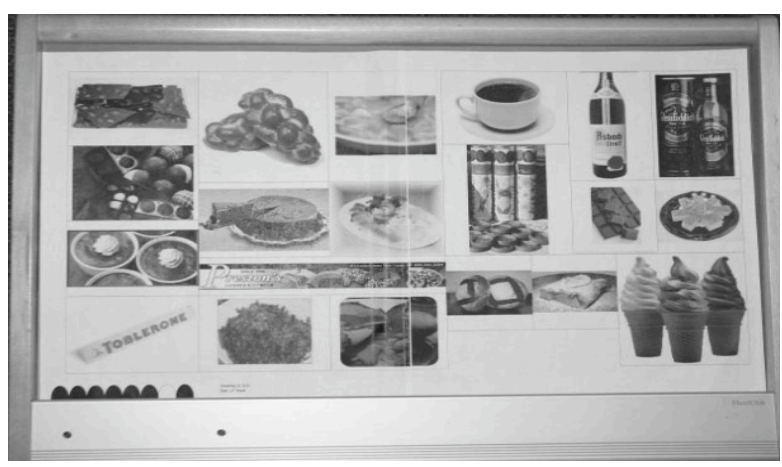

Board with 2-D symbols + print

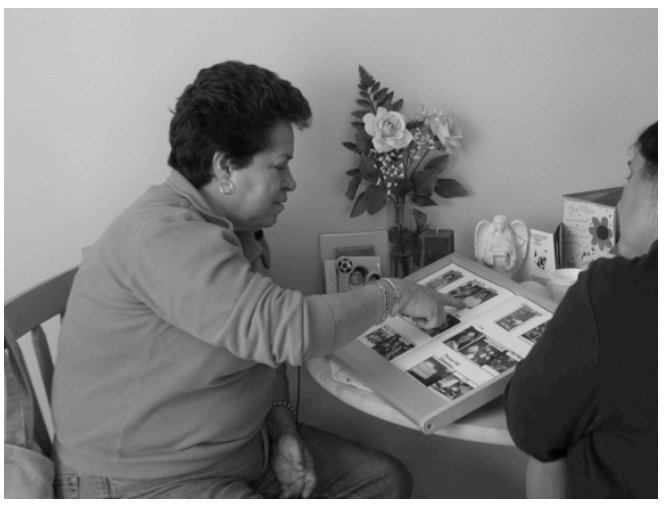




\section{Method}

1. Identify participant and randomly assign to condition for symbol type \& voice output

2. Determine participant's preferred topic and vocabulary

3. Develop communication device for condition

4. Conduct videotaped conversations with participant for various conditions in their homes

\section{Results for Voice Output}

- Fewer utterances with Voice Output ( $\mathrm{p}<$. 007)

- More Minimal Speech with Voice Output, especially one word utterances $(\mathrm{p}<.018)$

- Anecdotal evidence suggests participants are distracted by Voice Output
Participant randomization to symbol type \& voice output conditions

\begin{tabular}{|l|c|c|c|}
\cline { 2 - 4 } \multicolumn{1}{c|}{} & \multicolumn{3}{c|}{ Input Mode } \\
\hline \multicolumn{1}{c|}{ Output Mode } & Print only & $\begin{array}{c}2 \text { 2-D +Print } \\
\text { symbols }\end{array}$ & $\begin{array}{c}\text { 3-D + Print } \\
\text { symbols }\end{array}$ \\
\hline Voice output & $\mathbf{5}$ & $\mathbf{6}$ & $\mathbf{3}$ \\
\hline No voice output & $\mathbf{8}$ & $\mathbf{1 1}$ & $\mathbf{8}$ \\
\hline Total & $\mathbf{1 3}$ & $\mathbf{1 7}$ & $\mathbf{1 1}$ \\
\hline
\end{tabular}

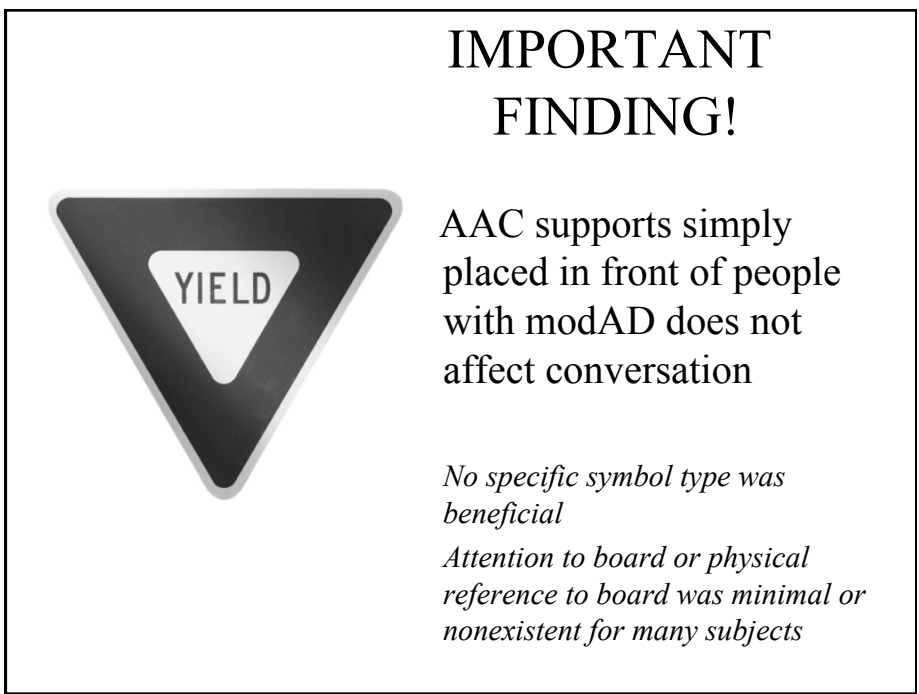



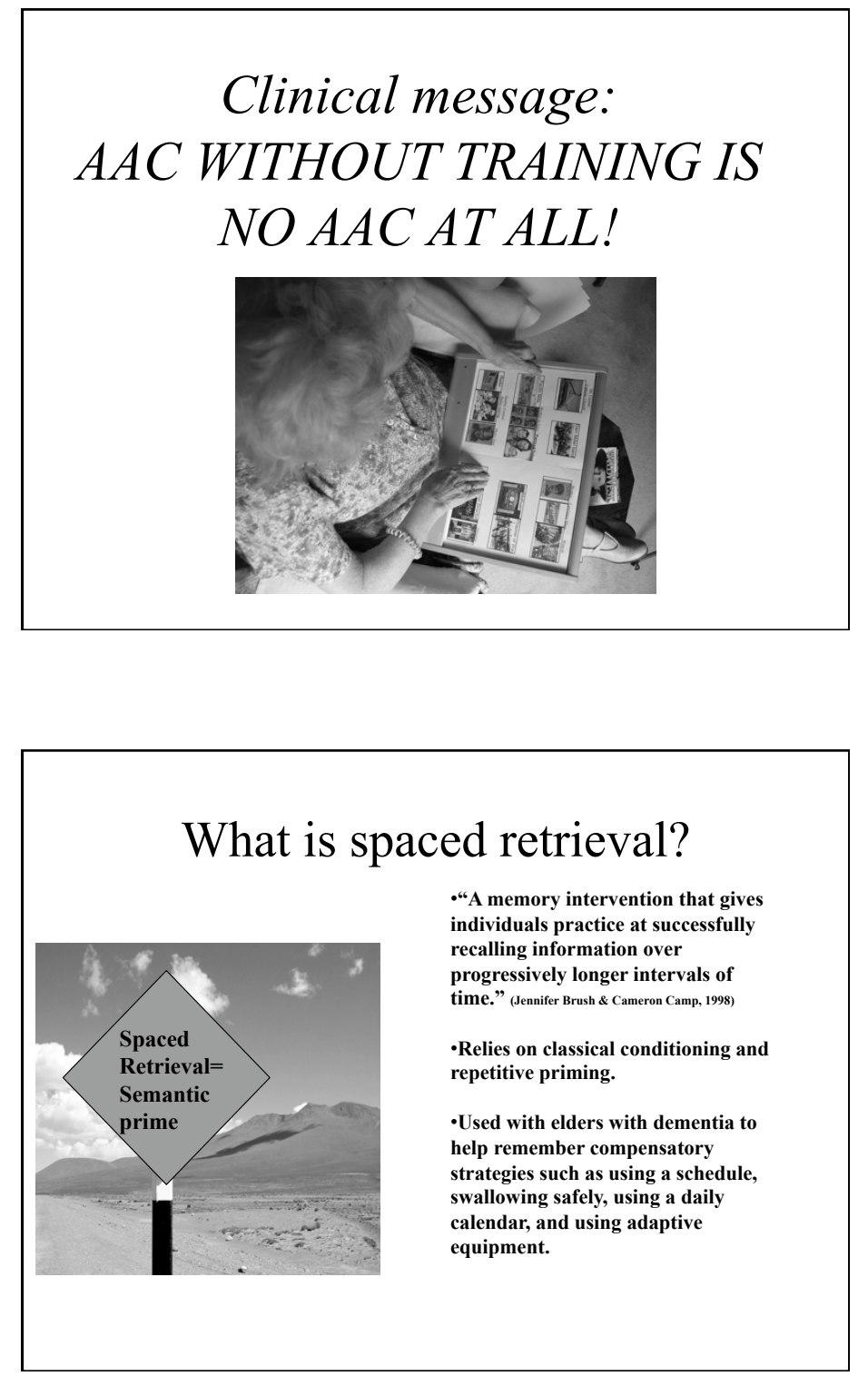

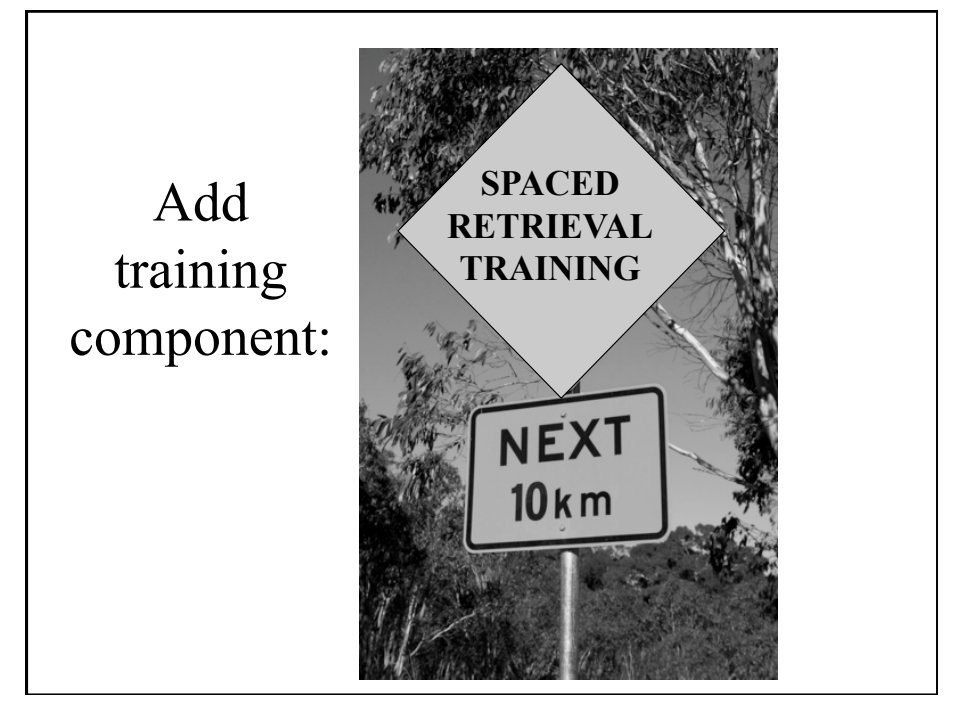

\section{Adjusted study design}

- Conditions varied within participants:

- 1 primed experimental condition

- 2 control conditions (no AAC device):

- Standard control

- Primed control

- 99 total conversations:

- 3 conversations/condition

- 9 conversations/participant 


\section{Add new dependent variables} closely tied to semantic primes

- Number of primed words used during conversation

- Number of utterances

- Percent 1-word utterances

- MLU in words

- Type-token ratio

- Number of references to AAC device

Used SALT software for transcription and analysis

(Systematic Analysis of Language Transcripts, Miller \& Chapman, 1986-2000)

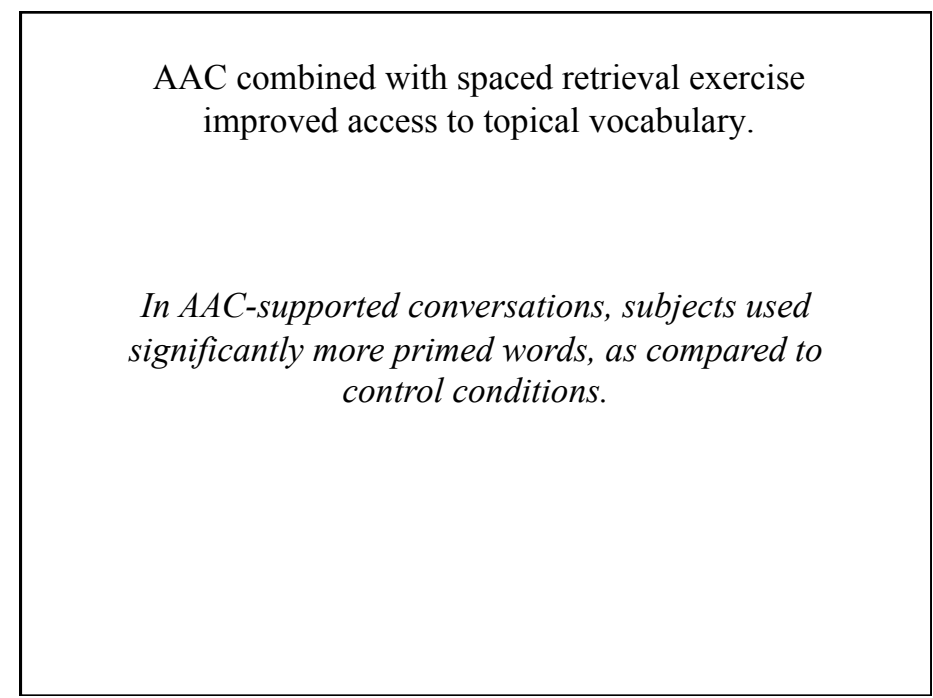

Results: Subjects used the AAC device more when conversations were primed.

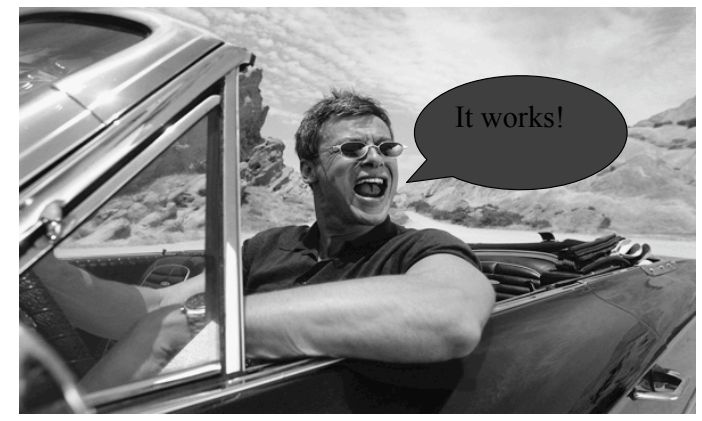

(References to AAC device during conversations quadrupled, as compared to untrained conversations)

\section{Priming Wins with AD!}

-AAC improves

conversation of adults

with modAD

- when training for

semantic priming is added

-to account for

attentional, perceptual, or

memory impairments that

interfere with

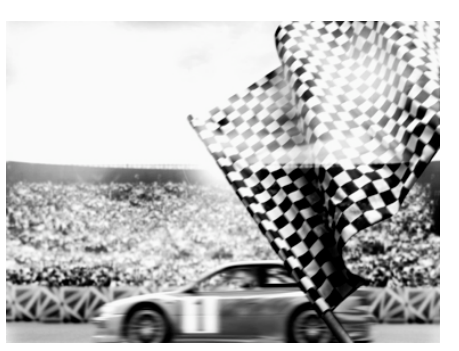

performance. 


\section{Early Stage Intervention}

- Learn about the patient and their primary communication partners $(\mathrm{Hx}$, interests, family, ADLs, travel, etc.)

- Integrally involve the patient in constructing "memory" booklets, word lists, hierarchy of difficult situations - always evolving

- All practice should occur with the primary communication partner for future success

- Teach/practice priming method

\section{Late Stage Intervention}

- Scale back communication books, boards to stress function, ADLs, basic choices, etc.

- Stress daily routines

- Constantly monitor communication partner's ability to facilitate use of tools

- Monitor use and success of priming

\section{Mid-Stage Intervention}

- Continue to teach/model priming techniques to communication partners.

- Capitalize on early learning and practice with communication partner to bulk up communication books

- Be mindful of text vs. pictures, drawings, visual scene display, array size, etc.

- Be mindful of comprehension difficulties (auditory, visual, orthographic)

\section{Assistive Technology without training is not assistive.}

- Rick Creech, A.T. user and advocate 


\begin{tabular}{|c|} 
Thanks for listening! \\
gibbons@,ohsu.edu \\
503-494-0378 \\
Chris Gibbons \\
\hline
\end{tabular}

